\title{
氮肥施用量对机插优质晚稻产量和稻米品质的影响
}

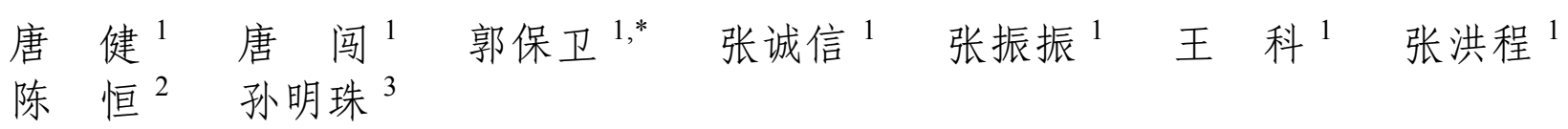

\author{
${ }^{1}$ 扬州大学江苏省作物栽培生理重点实验室 / 江苏省粮食作物现代产业技术协同创新中心, 江苏扬州 $225009 ;{ }^{2}$ 江西省上高县农业局, \\ 江西上高 $336400 ;{ }^{3}$ 江西省农业技术推广总站, 江西南昌 330046
}

摘 要: 本试验为篎选适合优质丰产机插晚稻的最佳氮肥用量, 以优质双季晚稻泰优 398 、黄华占、天优华占、美香 新占 4 个品种为试验材料, 在机插条件下设 $0 、 135 、 180 、 255 \mathrm{~kg} \mathrm{hm}^{-2}$ 四个施氮水平, 测定产量构成及稻米品质指标。 结果表明, 适当增施氮肥可增加优质双季晚稻产量, 施氮量为 $180 \mathrm{~kg} \mathrm{hm}^{-2}$ 时产量最高。除黄华占的整精米率外, 施 氮量为 $180 \mathrm{~kg} \mathrm{hm}^{-2}$ 时各品种的䊁米率、精米率和整精米率最高。随施氮量的增加, 机插优质双季晚稻的严白粒率和 严白度降低, 米粒长宽比变大, 蛋白质含量和胶稠度均增加, 直链淀粉含量减少; 峰值秥度、热浆黏度、崩解值、最 终黏度逐渐下降, 消减值增加, 糊化温度呈上升趋势。适当增施氮肥可改善机插优质晚稻加工品质、外观品质、蒸者 和营养品质, 但 RVA 特性有变劣趋势。1 $80 \mathrm{~kg} \mathrm{hm}^{-2}$ 的施氮量可使机插优质双季晚稻优质和高产达到较好的协调统一。 关键词: 机插; 优质晚稻; 氮肥用量; 产量; 稻米品质

\section{Effect of nitrogen application on yield and rice quality of mechanical trans- planting high quality late rice}

\author{
TANG Jian ${ }^{1}$, TANG Chuang ${ }^{1}$, GUO Bao-Wei ${ }^{1, *}$, ZHANG Cheng-Xin ${ }^{1}$, ZHANG Zhen-Zhen ${ }^{1}$, WANG Ke ${ }^{1}$, \\ ZHANG Hong-Cheng ${ }^{1}$, CHEN Heng ${ }^{2}$, and SUN Ming-Zhu ${ }^{3}$
}

\begin{abstract}
${ }^{1}$ Jiangsu Key Laboratory of Crop Cultivation and Physiology / Jiangsu Co-Innovation Center for Modern Production Technology of Grain Crops, Yangzhou University, Yangzhou 225009, Jiangsu, China; ${ }^{2}$ Bureau of Agriculture of Shanggao County of Jiangxi Province, Shanggao 336400, Jiangxi, China; ${ }^{3}$ Jiangxi Agricultural Technology Extension Station, Nanchang 330046, Jiangxi, China
\end{abstract}

\begin{abstract}
The experiment was conducted by using four high quality late rice varieties, including Taiyou 398, Huanghuazhan, Tianyouhuazhan, and Meixiangxinzhan under four nitrogen treatments of $0,135,180$, and $255 \mathrm{~kg} \mathrm{hm}^{-2}$ to select the optimum nitrogen application rate for the coordination of high quality and high yield. The appropriate increase of nitrogen application improved the yield of high quality rice, which reached maximum under the nitrogen treatment of $180 \mathrm{~kg} \mathrm{hm}^{-2}$. When the nitrogen application was $180 \mathrm{~kg} \mathrm{hm}^{-2}$, the indicators such as the brown rice rate, milled rice rate and head milled rice rate for all varieties reached maximum except for the head milled rice rate of Huanghuazhan. As more nitrogen was gradually applied, there were growing length-width ratio, protein content and gel consistency of double-season high-quality late rice while in contrast reduction in chalky grain percentage, chalkiness degree and amylose content, which also brought about a steady drop in peak viscosity, trough viscosity, breakdown, final viscosity while a rise in setback and pasting temperature. To sum up, the appropriate increase of nitrogen application can improve the processing quality, appearance quality, cooking and nutritional quality while deteriorate the RVA characteristics. The nitrogen application of $180 \mathrm{~kg} \mathrm{hm}^{-2}$ facilitates a better coordination between quality and yield in high quality double-season late rice under mechanical transplanting.
\end{abstract}

Keywords: mechanical transplanting; high quality late rice; nitrogen application; yield; rice quality

本研究由国家重点研发计划项目(2016YFD0300507), 国家自然科学基金项目(31601246), 国家现代农业产业技术体系建设专项 (CARS-01-27)和江苏高校优势学科建设工程项目资助。

This study was supported by the Grants from the National Key Research Program (2016YFD0300507), the National Natural Science Foundation of China (31601246), the National Modern Agricultural Industry Technology System Construction Special (CARS-01-27), and the Project Funded by the Priority Academic Program Development of Jiangsu Higher Education Institutions.

*通信作者(Corresponding author): 郭保卫, E-mail: gbwyx@126.com

第一作者联系方式: E-mail: 2841915943@qq.com

Received (收稿日期): 2019-03-05; Accepted (接受日期): 2019-08-09; Published online (网络出版日期): 2019-09-01.

URL: http://kns.cnki.net/kcms/detail/11.1809.S.20190910.0945.004.html 
我国是世界上水稻生产与消费的第一大国, 占 世界上水稻种植面积的 $1 / 5^{[1]}$ 。随着生活水平的提高, 人们不仅仅重视水稻高产, 还越来越追求高稻米品 质 ${ }^{[2]}$ 。水稻产量和稻米品质除受自身遗传基因、栽培 环境和气候条件等因素的影响外 ${ }^{[3-5]}$, 受氮肥的影响 较大。氮是水稻肥料的最重要成分并且显著影响水稻 生长发育 ${ }^{[6-7]}$, 对水稻的生理特性、产量形成有很大影 响及作用 ${ }^{[8]}$ 。氮肥施用过多不仅不能使作物产量增加, 还可能使作物产量降低, 使肥料吸收利用率和农学 效率降低, 污染环境, 造成资源浪费 ${ }^{[9]}$ 。关于氮肥施 用量对水稻产量和稻米品质的影响, 前人已有较多 的研究。郭保卫等 ${ }^{[10]}$ 研究认为随着施氮量增加, 机插 稻产量先增加后减少, 以施氮量为 $270 \mathrm{~kg} \mathrm{hm}^{-2}$ 产量 最高。徐新朋等 ${ }^{[11]}$ 研究表明合理氮肥用量可以显著增 加水稻有效穗数, 进而增加水稻产量。关于施氮对稻 米品质的影响, 多数研究认为随着氮肥用量的增加, 改善稻米的外观品质, 提高稻米的蛋白质含量, 使稻 米的蒸煮食味品质变差 ${ }^{[12-13]}$ 。朱大伟 ${ }^{[14]}$ 认为随施氮量 增加, 稻米的加工品质有所改善, 外观品质先改善后 变劣。金正勋等 ${ }^{[15]}$ 研究表明, 随着施氮量增加会使稻 米胶稠度变短, 直链淀粉含量下降, 导致米饭变得不 是很软, 而是增加了一定的硬度。金军等 ${ }^{[16]}$ 研究则指 出, 在一定的施氮水平范围内, 随施氮量的增加, 胶 稠度显著变长, 而施氮量再进一步增加, 则直链淀粉 和胶稠度无明显变化。稻米品质受遗传及栽培措施影 响较大, 加上生态环境及种植制度的不同, 众多研究 还未达成一致结论。前人研究针对高产水稻的氮肥利 用较多, 而有关机插条件下优质双季晚稻品种高产 和优质协调的氮肥调控方面研究较少。本试验通过系 统分析不同氮肥水平对机插优质晚稻产量和品质的 影响, 确定其最佳氮肥施用量, 为双季稻地区机插条 件下优质双季晚稻品种的氮肥合理施用提供理论依 据与技术支撑。

\section{1 材料与方法}

\section{1 试验地点及材料}

试验地点在江西省上高县泗溪镇曾家村。该地 年降水量为 $1630 \mathrm{~mm}$, 年均日照时数 $1730 \mathrm{~h}$, 年均 温度 $18.5^{\circ} \mathrm{C}$ 。试验田前茬为早稻, 土壤类型属沙壤 土, 地力中上等, 土壤含有机质 $24.46 \mathrm{~g} \mathrm{~kg}^{-1}$ 、速效 氮 $85.06 \mathrm{mg} \mathrm{kg}^{-1}$ 、速效磷 $47.22 \mathrm{mg} \mathrm{kg}$ 、速效钾 $71.69 \mathrm{mg} \mathrm{kg}^{-1}$ 。

以杂交籼稻泰优 398、天优华占与常规籼稻黄华
占、美香新占 4 个优质双季晚籼稻品种为试验材料。

\section{2 试验设计}

采用裂区设计, 以施氮(纯氮)水平为主区, 设 $0 、 135 、 180 、 255 \mathrm{~kg} \mathrm{hm}^{-2}$ 四个施氮水平, 分别用 $\mathrm{N} 0 、 \mathrm{~N} 1 、 \mathrm{~N} 2 、 \mathrm{~N} 3$ 表示，以品种为裂区。小区面积 为 $20 \mathrm{~m}^{2}, 3$ 次重复。不同施氮处理间做埂隔开, 用塑 料薄膜覆盖埂体, 保证各小区单独排灌, 防止串肥。

采用模拟毯苗机插方式。播种日期分别是 2017 年 6 月 28 日和 2018 年 6 月 27 日, 采用基质育秧, 4.5 叶左右移栽, 移栽期分别是 2017 年 7 月 25 日和 2018 年 7 月 16 日。栽插行株距为 $25 \mathrm{~cm} \times 13 \mathrm{~cm}$, 每穴 2 苗。氮肥按基肥: 菜肥: 穗肥比例为 5: $2: 3$ 施用, 分菜肥于移栽后 $7 \mathrm{~d}$ 一次性施用, 穗肥于倒四叶时 期施用, 氮 $($ 纯 $\mathrm{N})$ : 磷 $\left(\mathrm{P}_{2} \mathrm{O}_{5}\right)$ ：钾 $\left(\mathrm{K}_{2} \mathrm{O}\right)$ 比例为 3 : 1: 2, 磷肥一次性基施, 钾肥分别于移栽前、穗肥期 等量施入。移栽至有效分蒒期, 田间保持浅水灌溉; 当 群体茎藍数达预期穗数 $80 \%$ 时开始排水轻搁田, 待田 间丰产沟不见水时再灌溉，直到拔节期; 拔节期到成 熟期湿润灌溉, 干湿交替, 周而复始直到成熟前 1 周。 其他栽培管理措施按照优质高产要求统一实施。

\section{3 测定项目与方法}

1.3.1 产量测定水稻成熟期, 从每小区选取水 稻 100 穴, 计算有效穗数。从各处理按照平均穗数 取 5 穴调查每穗粒数、结实率和测定千粒重, 重复 3 次, 计算理论产量。从每小区收割 50 穴, 测定水分, 去除杂质, 折算实际产量。

1.3.2 稻米品质测定水稻收获脱粒, 晒干, 室 内咜藏 3 个月后, 用风选机风选后, 参考国家标准 《GB/T 17891-1999 优质稻谷》测定稻米的加工品 质、外观品质、蒸煮食味品质和营养品质等主要品 质指标。采用瑞典 Foss Tecator 公司生产的近红外谷 物分析仪(Infrared 1241 Grain Analyzer)测定精米的 蛋白质含量和直链淀粉含量。

\subsection{3 稻米淀粉黏滞特性采用澳大利亚 Newport} Scientific 仪器公司生产的 Super 3 型 RVA 仪(Rapid Viscosity-Analyzer)快速测定淀粉谱黏滞特性, 用 $\mathrm{T}$ C W (Thermal Cycle for Windows)配套软件分析淀粉 黏滞性 ${ }^{[17]}$ 。

1.3.4 温光资料灌浆结实期间的逐日最高温 度、最低温度、平均温度和日照时数等资料取自江 西省上高县气象局。

\section{4 数据统计分析}

采用 Microsoft Excel 2016 录入、整理和计算数 
据, 运用 DPS 数据处理系统进行分析, 数据间的多 重比较采用 LSD 法。

\section{2 结果与分析}

\section{1 氮肥施用量对优质晚稻产量及构成因素的 影响}

各优质晚稻品种两年的产量均表现为 $N 2>N 3>$
$\mathrm{N} 1>\mathrm{N} 0, \mathrm{~N} 2$ 时产量最高(表 1), N3 时产量有所下降, 其中 N2、N3 的产量无显著差异, 但均显著高于 N0、N1。4 个品种中，天优华占和黄华占的产量 增幅大。

从产量构成因子来看，随着施氮量的增加，各 品种的穗数增加, 每穗粒数随施氮量先增后减, 在 N2 时最高, N3 时有所下降, 且 N2 与 N3 处理间没有

表 1 不同氮肥施用量下优质晚稻产量及其构成因素

Table 1 Yield and composition of high quality late rice under different nitrogen application rates

\begin{tabular}{|c|c|c|c|c|c|c|c|c|}
\hline $\begin{array}{c}\text { 品种 } \\
\text { Cultivar }\end{array}$ & $\begin{array}{c}\text { 处理 } \\
\text { Treatment }\end{array}$ & $\begin{array}{c}\text { 穗数 } \\
\text { Panicle } \\
\left(\times 10^{4} \mathrm{hm}^{-2}\right)\end{array}$ & $\begin{array}{c}\text { 每穗粒数 } \\
\text { Spikelets per } \\
\text { panicle }\end{array}$ & $\begin{array}{l}\text { 总颖花量 } \\
\text { Total number } \\
\text { of spikelets } \\
\left(\times 10^{4} \mathrm{hm}^{-2}\right) \\
\end{array}$ & $\begin{array}{c}\text { 结实率 } \\
\text { Seed-setting rate } \\
(\%)\end{array}$ & $\begin{array}{c}\text { 千粒重 } \\
\text { 1000-kernel } \\
\text { weight } \\
\text { (g) }\end{array}$ & $\begin{array}{c}\text { 理论产量 } \\
\text { Theoretical } \\
\text { yield } \\
\left(\mathrm{kg} \mathrm{hm}^{-2}\right) \\
\end{array}$ & $\begin{array}{c}\text { 实际产量 } \\
\text { Actual } \\
\text { yield } \\
\left(\mathrm{kg} \mathrm{hm}^{-2}\right) \\
\end{array}$ \\
\hline \multicolumn{9}{|l|}{2017} \\
\hline 美香新占 & No & $295.50 \mathrm{Bb}$ & $127.39 \mathrm{Bc}$ & $37643.45 \mathrm{Cc}$ & $83.43 \mathrm{Aa}$ & $20.35 \mathrm{Aa}$ & $6391.11 \mathrm{Cc}$ & $6218.51 \mathrm{Cc}$ \\
\hline \multirow{3}{*}{$\begin{array}{l}\text { Meixiang- } \\
\text { xinzhan }\end{array}$} & N1 & $347.82 \mathrm{ABa}$ & $146.36 \mathrm{ABb}$ & $50907.50 \mathrm{Bb}$ & $77.79 \mathrm{ABb}$ & $20.05 \mathrm{Aab}$ & $7939.99 \mathrm{Bb}$ & 7497.38 Bb \\
\hline & $\mathrm{N} 2$ & $354.63 \mathrm{Aa}$ & $157.26 \mathrm{Aa}$ & $55768.68 \mathrm{Aa}$ & $77.74 \mathrm{ABb}$ & $19.25 \mathrm{Ab}$ & $8345.75 \mathrm{Aa}$ & $8204.39 \mathrm{Aa}$ \\
\hline & N3 & $357.92 \mathrm{Aa}$ & $156.04 \mathrm{Aa}$ & $55849.66 \mathrm{Aa}$ & $77.15 \mathrm{Bb}$ & 19.17 Aab & $8186.72 \mathrm{ABa}$ & $8096.84 \mathrm{ABa}$ \\
\hline 泰优 398 & No & $304.88 \mathrm{Cc}$ & $117.36 \mathrm{Bb}$ & $35780.99 \mathrm{Cc}$ & $82.21 \mathrm{Aa}$ & $22.57 \mathrm{Aa}$ & $6639.09 \mathrm{Bc}$ & $6495.88 \mathrm{Bc}$ \\
\hline \multirow[t]{3}{*}{ Taiyou 398} & N1 & $341.09 \mathrm{Bb}$ & $129.04 \mathrm{Aa}$ & $44014.31 \mathrm{Bb}$ & 79.28 ABab & $22.41 \mathrm{Aa}$ & $7819.87 \mathrm{Ab}$ & $7342.58 \mathrm{ABb}$ \\
\hline & N2 & $367.41 \mathrm{ABa}$ & $131.02 \mathrm{Aa}$ & $48137.55 \mathrm{Aa}$ & $76.83 \mathrm{ABbc}$ & $22.35 \mathrm{Aa}$ & $8265.94 \mathrm{Aa}$ & $7928.13 \mathrm{Aa}$ \\
\hline & N3 & $377.66 \mathrm{Aa}$ & $129.25 \mathrm{Aa}$ & $48812.10 \mathrm{Aa}$ & $75.02 \mathrm{Bc}$ & $22.30 \mathrm{Aa}$ & $8166.00 \mathrm{Aa}$ & $7733.12 \mathrm{Aa}$ \\
\hline 天优华占 & No & $269.72 \mathrm{Cc}$ & $111.37 \mathrm{Cc}$ & $30039.25 \mathrm{Cc}$ & $90.81 \mathrm{Aa}$ & $23.57 \mathrm{Aa}$ & $6456.85 \mathrm{Bc}$ & $6203.33 \mathrm{Bc}$ \\
\hline \multirow{3}{*}{$\begin{array}{l}\text { Tianyouhua- } \\
\text { zhan }\end{array}$} & N1 & $285.15 \mathrm{BCb}$ & $133.18 \mathrm{Bb}$ & $37975.94 \mathrm{Bb}$ & $88.43 \mathrm{Aab}$ & $23.40 \mathrm{Aa}$ & $7858.22 \mathrm{ABb}$ & $7565.08 \mathrm{Ab}$ \\
\hline & $\mathrm{N} 2$ & $292.93 \mathrm{Bb}$ & $154.12 \mathrm{Aa}$ & $45146.24 \mathrm{Aa}$ & $86.38 \mathrm{ABb}$ & $23.30 \mathrm{Aa}$ & $9086.38 \mathrm{Aa}$ & $8608.62 \mathrm{Aa}$ \\
\hline & $\mathrm{N} 3$ & $315.88 \mathrm{Aa}$ & $150.32 \mathrm{Aa}$ & $47482.38 \mathrm{Aa}$ & $82.14 \mathrm{Bc}$ & $23.19 \mathrm{Aa}$ & $9005.57 \mathrm{Aa}$ & $8517.32 \mathrm{Aa}$ \\
\hline 黄华占 & No & $285.21 \mathrm{Bb}$ & $105.05 \mathrm{Cc}$ & $29961.58 \mathrm{Cc}$ & $92.04 \mathrm{Aa}$ & $22.11 \mathrm{Aa}$ & $6097.19 \mathrm{Bc}$ & $5941.71 \mathrm{Bc}$ \\
\hline \multirow[t]{3}{*}{ Huanghuazhan } & N1 & $334.41 \mathrm{ABa}$ & $112.96 \mathrm{Bb}$ & $37775.11 \mathrm{Bb}$ & $91.45 \mathrm{ABa}$ & $21.87 \mathrm{Aa}$ & $7555.06 \mathrm{Ab}$ & $6987.72 \mathrm{ABb}$ \\
\hline & $\mathrm{N} 2$ & $337.41 \mathrm{ABa}$ & $121.92 \mathrm{Aa}$ & $41137.03 \mathrm{Aa}$ & $91.09 \mathrm{ABa}$ & $21.75 \mathrm{Aa}$ & $8112.63 \mathrm{Aa}$ & $7948.39 \mathrm{Aa}$ \\
\hline & $\mathrm{N} 3$ & $354.47 \mathrm{Aa}$ & $119.68 \mathrm{Aa}$ & $42423.47 \mathrm{Aa}$ & $88.09 \mathrm{Bb}$ & $21.68 \mathrm{Aa}$ & $8027.25 \mathrm{Aa}$ & $7870.37 \mathrm{Aa}$ \\
\hline \multicolumn{9}{|l|}{2018} \\
\hline 美香新占 & No & $304.77 \mathrm{Bc}$ & $103.30 \mathrm{Bb}$ & $31482.50 \mathrm{Bc}$ & $86.17 \mathrm{Aa}$ & $21.10 \mathrm{Aa}$ & $5724.27 \mathrm{Bb}$ & $5602.80 \mathrm{Bc}$ \\
\hline Meixiang- & N1 & $317.08 \mathrm{ABbc}$ & $144.50 \mathrm{Aa}$ & $45818.28 \mathrm{Ab}$ & $84.16 \mathrm{Aab}$ & $20.12 \mathrm{Aab}$ & $7750.88 \mathrm{Aa}$ & $7326.74 \mathrm{Ab}$ \\
\hline \multirow[t]{2}{*}{ xinzhan } & $\mathrm{N} 2$ & $326.32 \mathrm{ABb}$ & $148.54 \mathrm{Aa}$ & $48470.61 \mathrm{Aab}$ & $83.79 \mathrm{Ab}$ & $19.80 \mathrm{Ab}$ & $8041.17 \mathrm{Aa}$ & $7757.72 \mathrm{Aa}$ \\
\hline & N3 & $354.02 \mathrm{Aa}$ & $142.97 \mathrm{Aa}$ & $50615.57 \mathrm{Aa}$ & $83.37 \mathrm{Ab}$ & $19.75 \mathrm{Ab}$ & $7912.05 \mathrm{Aa}$ & 7634.58 Aab \\
\hline 泰优 398 & No & $273.98 \mathrm{Bc}$ & $97.22 \mathrm{Bc}$ & $26637.24 \mathrm{Bc}$ & $87.29 \mathrm{Aa}$ & $24.25 \mathrm{Aa}$ & $5638.66 \mathrm{Cc}$ & $5910.65 \mathrm{Bc}$ \\
\hline \multirow[t]{3}{*}{ Taiyou 398} & N1 & $338.63 \mathrm{Aa}$ & $113.77 \mathrm{Ab}$ & $38526.95 \mathrm{Ab}$ & 85.69 Aab & $24.20 \mathrm{Aa}$ & $7989.63 \mathrm{Bb}$ & $7449.88 \mathrm{Ab}$ \\
\hline & $\mathrm{N} 2$ & $347.87 \mathrm{Aab}$ & $121.08 \mathrm{Aa}$ & $42120.79 \mathrm{Aa}$ & $85.14 \mathrm{Ab}$ & $23.90 \mathrm{Aa}$ & $8571.00 \mathrm{Aa}$ & 8127.14 Aa \\
\hline & $\mathrm{N} 3$ & $354.02 \mathrm{Ab}$ & $117.75 \mathrm{Aab}$ & 41686.22 Aab & $84.74 \mathrm{Ab}$ & $23.85 \mathrm{Aa}$ & $8425.41 \mathrm{ABa}$ & $7942.43 \mathrm{Aa}$ \\
\hline 天优华占 & No & $283.77 \mathrm{Ac}$ & $97.00 \mathrm{Cc}$ & $27525.47 \mathrm{Cc}$ & $85.43 \mathrm{Aa}$ & $24.80 \mathrm{Aa}$ & $5831.91 \mathrm{Cc}$ & $5610.65 \mathrm{Bc}$ \\
\hline \multirow{3}{*}{$\begin{array}{l}\text { Tianyouhua- } \\
\text { zhan }\end{array}$} & N1 & $306.42 \mathrm{Ab}$ & $131.32 \mathrm{Bb}$ & $40239.12 \mathrm{Bb}$ & 83.09 ABab & $24.60 \mathrm{Aa}$ & $8225.20 \mathrm{Bb}$ & $7816.15 \mathrm{Ab}$ \\
\hline & $\mathrm{N} 2$ & $324.58 \mathrm{Aa}$ & $145.83 \mathrm{Aa}$ & $47334.81 \mathrm{Aa}$ & $80.51 \mathrm{ABbc}$ & $24.45 \mathrm{Aa}$ & $9280.08 \mathrm{Aa}$ & $8831.26 \mathrm{Aa}$ \\
\hline & N3 & $335.54 \mathrm{Aa}$ & $141.50 \mathrm{ABa}$ & $47478.53 \mathrm{Aa}$ & $79.36 \mathrm{Bc}$ & $24.40 \mathrm{Aa}$ & $9156.49 \mathrm{Aa}$ & $8646.55 \mathrm{Aa}$ \\
\hline 黄华占 & No & $286.53 \mathrm{Ac}$ & $96.65 \mathrm{Bb}$ & $27693.35 \mathrm{Cc}$ & $90.65 \mathrm{Aa}$ & $22.80 \mathrm{Aa}$ & $5723.56 \mathrm{Bc}$ & $5699.08 \mathrm{Cc}$ \\
\hline \multirow[t]{3}{*}{ Huanghuazhan } & N1 & $318.18 \mathrm{Ab}$ & $119.71 \mathrm{Aa}$ & $38089.35 \mathrm{Bb}$ & $89.22 \mathrm{Aab}$ & $22.75 \mathrm{Aa}$ & $7731.50 \mathrm{Ab}$ & $7345.75 \mathrm{Bb}$ \\
\hline & N2 & $338.32 \mathrm{Aa}$ & $123.34 \mathrm{Aa}$ & $41728.23 \mathrm{Aa}$ & $88.49 \mathrm{Aab}$ & $22.65 \mathrm{Aa}$ & $8363.81 \mathrm{Aa}$ & $8180.86 \mathrm{Aa}$ \\
\hline & $\mathrm{N} 3$ & $341.40 \mathrm{Aa}$ & $120.93 \mathrm{Aa}$ & $41284.46 \mathrm{Aa}$ & $87.92 \mathrm{Ab}$ & $22.60 \mathrm{Aa}$ & $8203.12 \mathrm{Aa}$ & $7996.15 \mathrm{ABa}$ \\
\hline
\end{tabular}

标以不同大、小写字母的值分别在 0.01 和 0.05 水平差异显著。 $\mathrm{N} 0:$ 不施氮肥; $\mathrm{N} 1: 135 \mathrm{~kg} \mathrm{hm}^{-2}$ 纯氮; $\mathrm{N} 2: 180 \mathrm{~kg} \mathrm{hm}^{-2}$ 纯氮; $\mathrm{N} 3: 255 \mathrm{~kg}$ $\mathrm{hm}^{-2}$ 纯氮。

Values followed by different letters are significantly different at the 0.01 and 0.05 probability levels, respectively. N0: no N applied; N1: 135 $\mathrm{kg} \mathrm{hm}^{-2} \mathrm{~N}$ applied; $\mathrm{N} 2: 180 \mathrm{~kg} \mathrm{hm}^{-2} \mathrm{~N}$ applied; N3: $255 \mathrm{~kg} \mathrm{hm}^{-2} \mathrm{~N}$ applied. 
显著差异。四品种的结实率和千粒重均随施氮量的 增加而降低, 除黄华占的结实率外, 其他品种的 N0 处理均显著或极显著高于 N2、N3。泰优 398、天优 华占和黄华占的千粒重表现为各处理间无显著差异, 美香新占 N0 处理的千粒重显著高于 N2、N3, 且 N2 和 N3 处理间没有显著差异。可见, 施氮量对 4 个品 种的穗数、每穗粒数影响较大, 对结实率影响次之, 对千粒重影响较小。

\section{2 氮肥施用量对优质晚稻稻米品质和 RVA 谱} 特性的影响

\subsection{1 加工品质随着施氮量的增加, 各品种的} 糙米率和精米率先增加后降低, 并在 N2 时达到最 大(表 2), 其中除 2017 年的美香新占和黄华占及 2018 年的黄华占外, N2 处理的䊁米率均显著高于 N0 处理, 除了 2017 年的天优华占外, N2 处理的精米 率也均显著高于 N0 处理。整精米率表现跟䊁米率一 样趋势, 除了黄华占外, 也在氮肥水平为 $\mathrm{N} 2$ 时达到
最大, 黄华占的整精米率在 $\mathrm{N} 3$ 处理时达到最大, 所 有品种 N2 处理整精米均显著或极显著高于 N0 处 理。由此可见氮肥施用量控制在合理的范围内, 可 以提高双季晚稻的加工品质。

\subsection{2 外观品质 随氮肥量的增加, 4 个品种的整} 精米粒长和长宽比均增加, 除 2018 年天优华占的粒 长外, 其余品种各处理间无显著差异(表 3)。各品种 严白粒率、严白度均随氮肥量的增加而下降, N2 处理 的严白粒率、严白度显著或极显著低于 N0 处理。可 见适当增加氮肥施用量, 可以改善稻米的外观品质。

2.2.3 蒸煮和营养品质各品种的直链淀粉含量 均随着施氮量增加而下降, 其中 N2、N3 处理与 $\mathrm{N} 0$ 处理差异显著或极显著, N2 与 $\mathrm{N} 3$ 处理差异不显著 (表 4)。胶稠度和蛋白质含量均随施氮量增加而增加, 除了 2017 年天优华占的蛋白质含量外, 其他品种 $\mathrm{N} 2 、 \mathrm{~N} 3$ 处理的胶稠度和蛋白质含量均与 N0 处理差 异显著或极显著。

表 2 不同氮肥施用量下优质晚稻加工品质

Table 2 Processing quality of high quality late rice under different nitrogen application rates (\%)

\begin{tabular}{|c|c|c|c|c|c|c|c|}
\hline \multirow{2}{*}{$\begin{array}{c}\text { 品种 } \\
\text { Cultivar }\end{array}$} & \multirow{2}{*}{$\begin{array}{c}\text { 处理 } \\
\text { Treatment }\end{array}$} & \multicolumn{3}{|c|}{2017} & \multicolumn{3}{|c|}{2018} \\
\hline & & $\begin{array}{c}\text { 糙米率 } \\
\mathrm{BR}\end{array}$ & $\begin{array}{c}\text { 精米率 } \\
\text { MR }\end{array}$ & $\begin{array}{c}\text { 整精米率 } \\
\text { HMR }\end{array}$ & $\begin{array}{c}\text { 糙米率 } \\
\mathrm{BR}\end{array}$ & $\begin{array}{c}\text { 精米率 } \\
\text { MR }\end{array}$ & $\begin{array}{c}\text { 整精米率 } \\
\text { HMR }\end{array}$ \\
\hline \multirow{4}{*}{$\begin{array}{c}\text { 美香新占 } \\
\text { Meixiangxinzhan }\end{array}$} & No & $78.41 \mathrm{Aa}$ & $68.67 \mathrm{Ab}$ & $58.94 \mathrm{Ab}$ & $77.01 \mathrm{Ab}$ & $70.71 \mathrm{Ab}$ & $53.58 \mathrm{Bb}$ \\
\hline & N1 & $78.67 \mathrm{Aa}$ & $69.48 \mathrm{Ab}$ & $59.72 \mathrm{Aab}$ & $80.98 \mathrm{Aa}$ & $73.60 \mathrm{Aa}$ & $55.28 \mathrm{ABb}$ \\
\hline & $\mathrm{N} 2$ & $79.30 \mathrm{Aa}$ & $70.74 \mathrm{Aa}$ & $62.25 \mathrm{Aa}$ & $81.20 \mathrm{Aa}$ & $73.88 \mathrm{Aa}$ & $58.02 \mathrm{Aa}$ \\
\hline & N3 & $78.82 \mathrm{Aa}$ & $70.21 \mathrm{Aab}$ & $59.51 \mathrm{Aab}$ & $81.10 \mathrm{Aa}$ & $69.96 \mathrm{Ab}$ & $54.87 \mathrm{ABb}$ \\
\hline \multirow{4}{*}{$\begin{array}{c}\text { 泰优 } 398 \\
\text { Taiyou } 398\end{array}$} & No & $79.70 \mathrm{Ab}$ & $66.56 \mathrm{Ab}$ & $53.58 \mathrm{Abc}$ & $78.29 \mathrm{Ab}$ & $63.58 \mathrm{Ab}$ & $50.99 \mathrm{Ab}$ \\
\hline & N1 & $80.63 \mathrm{Aab}$ & 69.17 Aab & $55.16 \mathrm{Aab}$ & 79.68 Aab & $67.91 \mathrm{Aab}$ & $53.97 \mathrm{Aab}$ \\
\hline & $\mathrm{N} 2$ & $81.98 \mathrm{Aa}$ & $70.12 \mathrm{Aa}$ & $57.07 \mathrm{Aa}$ & $81.74 \mathrm{Aa}$ & $70.23 \mathrm{Aa}$ & $57.75 \mathrm{Aa}$ \\
\hline & N3 & $81.00 \mathrm{Aab}$ & $69.90 \mathrm{Aab}$ & $52.33 \mathrm{Ac}$ & $81.81 \mathrm{Aa}$ & $69.68 \mathrm{Aa}$ & $52.19 \mathrm{Aab}$ \\
\hline \multirow{4}{*}{$\begin{array}{c}\text { 天优华占 } \\
\text { Tianyouhuazhan }\end{array}$} & No & $80.10 \mathrm{Ab}$ & $70.70 \mathrm{Aa}$ & $63.10 \mathrm{Bc}$ & $77.93 \mathrm{Ac}$ & $68.99 \mathrm{Ab}$ & $60.85 \mathrm{Bc}$ \\
\hline & N1 & $80.14 \mathrm{Ab}$ & $71.22 \mathrm{Aa}$ & $65.89 \mathrm{ABb}$ & $81.08 \mathrm{Aab}$ & $70.25 \mathrm{Aab}$ & $64.05 \mathrm{ABb}$ \\
\hline & $\mathrm{N} 2$ & $82.71 \mathrm{Aa}$ & $71.61 \mathrm{Aa}$ & $68.72 \mathrm{Aa}$ & $82.31 \mathrm{Aa}$ & $72.98 \mathrm{Aa}$ & $67.78 \mathrm{Aa}$ \\
\hline & N3 & $81.51 \mathrm{Aab}$ & $71.29 \mathrm{Aa}$ & $61.67 \mathrm{Bc}$ & $79.72 \mathrm{Abc}$ & $71.89 \mathrm{Aa}$ & $59.54 \mathrm{Bc}$ \\
\hline \multirow{4}{*}{$\begin{array}{c}\text { 黄华占 } \\
\text { Huanghuazhan }\end{array}$} & No & $81.12 \mathrm{Aa}$ & $69.46 \mathrm{Ab}$ & $45.15 \mathrm{Bc}$ & $79.77 \mathrm{Aa}$ & $68.36 \mathrm{Ab}$ & $45.56 \mathrm{Cc}$ \\
\hline & N1 & $81.24 \mathrm{Aa}$ & $70.00 \mathrm{Aab}$ & $48.99 \mathrm{ABbc}$ & $80.56 \mathrm{Aa}$ & $68.97 \mathrm{Ab}$ & $48.14 \mathrm{BCb}$ \\
\hline & $\mathrm{N} 2$ & $82.51 \mathrm{Aa}$ & $70.63 \mathrm{Aa}$ & $53.11 \mathrm{Aab}$ & $80.68 \mathrm{Aa}$ & $70.13 \mathrm{Aa}$ & $52.32 \mathrm{ABa}$ \\
\hline & N3 & $82.01 \mathrm{Aa}$ & $69.21 \mathrm{Ab}$ & $54.13 \mathrm{Aa}$ & $79.44 \mathrm{Aa}$ & $68.87 \mathrm{Ab}$ & $54.67 \mathrm{Aa}$ \\
\hline
\end{tabular}

标以不同大、小写字母的值分别在 0.01 和 0.05 水平差异显著。 $\mathrm{N} 0:$ 不施氮肥; $\mathrm{N} 1: 135 \mathrm{~kg} \mathrm{hm}^{-2}$ 纯氮; $\mathrm{N} 2: 180 \mathrm{~kg} \mathrm{hm}^{-2}$ 纯氮; $\mathrm{N} 3: 255 \mathrm{~kg} \mathrm{hm}{ }^{-2}$ 纯氮。

Values followed by different letters are significantly different at the 0.01 and 0.05 probability levels, respectively. N0: no N applied; N1: 135 $\mathrm{kg} \mathrm{hm}^{-2} \mathrm{~N}$ applied; N2: $180 \mathrm{~kg} \mathrm{hm}^{-2} \mathrm{~N}$ applied; N3: $255 \mathrm{~kg} \mathrm{hm}^{-2} \mathrm{~N}$ applied; BR: brown rice rate; MR: milled rice rate; HMR: head milled rice rate. 
表 3 不同氮肥施用量下优质晚稻外观品质

Table 3 Appearance quality of high quality late rice under different nitrogen application rates

\begin{tabular}{|c|c|c|c|c|c|c|c|c|c|}
\hline \multirow{2}{*}{$\begin{array}{c}\text { 品种 } \\
\text { Cultivar }\end{array}$} & \multirow{2}{*}{$\begin{array}{c}\text { 处理 } \\
\text { Treatment }\end{array}$} & \multicolumn{4}{|c|}{2017} & \multicolumn{4}{|c|}{2018} \\
\hline & & $\begin{array}{c}\text { 粒长 } \\
\mathrm{KL}(\mathrm{mm})\end{array}$ & $\begin{array}{c}\text { 长宽比 } \\
\text { L/W }\end{array}$ & $\begin{array}{c}\text { 严白粒率 } \\
\text { CR }(\%)\end{array}$ & $\begin{array}{l}\text { 普白度 } \\
\text { CD (\%) }\end{array}$ & $\begin{array}{c}\text { 粒长 } \\
\mathrm{KL}(\mathrm{mm})\end{array}$ & $\begin{array}{c}\text { 长宽比 } \\
\text { L/W }\end{array}$ & $\begin{array}{c}\text { 严白粒率 } \\
\text { CR }(\%)\end{array}$ & $\begin{array}{l}\text { 普白度 } \\
\mathrm{CD}(\%)\end{array}$ \\
\hline 美香新占 & No & $6.07 \mathrm{Aa}$ & $3.12 \mathrm{Aa}$ & $13.90 \mathrm{Aa}$ & $2.95 \mathrm{Aa}$ & $6.05 \mathrm{Aa}$ & $3.18 \mathrm{Aa}$ & $18.00 \mathrm{Aa}$ & $5.17 \mathrm{Aa}$ \\
\hline \multirow{3}{*}{$\begin{array}{c}\text { Meixiang } \\
\text { xinzhan }\end{array}$} & N1 & $6.12 \mathrm{Aa}$ & $3.16 \mathrm{Aa}$ & $12.94 \mathrm{ABa}$ & $2.63 \mathrm{Aa}$ & $6.30 \mathrm{Aa}$ & $3.33 \mathrm{Aa}$ & $15.04 \mathrm{Bb}$ & $3.64 \mathrm{Bb}$ \\
\hline & N2 & $6.15 \mathrm{Aa}$ & $3.17 \mathrm{Aa}$ & $10.98 \mathrm{BCb}$ & $2.45 \mathrm{ABb}$ & $6.35 \mathrm{Aa}$ & $3.35 \mathrm{Aa}$ & $13.12 \mathrm{Cc}$ & $3.17 \mathrm{Bc}$ \\
\hline & N3 & $6.28 \mathrm{Aa}$ & $3.23 \mathrm{Aa}$ & $9.90 \mathrm{Cb}$ & $2.30 \mathrm{Bb}$ & $6.42 \mathrm{Aa}$ & $3.36 \mathrm{Aa}$ & $11.89 \mathrm{Cd}$ & $2.59 \mathrm{Cd}$ \\
\hline 泰优 398 & No & $5.91 \mathrm{Aa}$ & $3.00 \mathrm{Aa}$ & $18.94 \mathrm{Aa}$ & $3.91 \mathrm{Aa}$ & $6.23 \mathrm{Aa}$ & $3.33 \mathrm{Ab}$ & $18.62 \mathrm{Aa}$ & $5.59 \mathrm{Aa}$ \\
\hline \multirow[t]{3}{*}{ Taiyou 398} & N1 & $5.99 \mathrm{Aa}$ & $3.02 \mathrm{Aa}$ & 17.18 Aab & $2.91 \mathrm{Bb}$ & $6.59 \mathrm{Aa}$ & $3.57 \mathrm{Aab}$ & $17.41 \mathrm{Aa}$ & $4.70 \mathrm{Bb}$ \\
\hline & $\mathrm{N} 2$ & $6.06 \mathrm{Aa}$ & $3.05 \mathrm{Aa}$ & $13.90 \mathrm{Bc}$ & $2.65 \mathrm{Bb}$ & $6.62 \mathrm{Aa}$ & $3.59 \mathrm{Aab}$ & $15.68 \mathrm{Ab}$ & $3.76 \mathrm{Cc}$ \\
\hline & N3 & $6.13 \mathrm{Aa}$ & $3.09 \mathrm{Aa}$ & $10.29 \mathrm{Cd}$ & $2.15 \mathrm{Bb}$ & $6.69 \mathrm{Aa}$ & $3.65 \mathrm{Aa}$ & $11.57 \mathrm{Ac}$ & $2.55 \mathrm{Dd}$ \\
\hline 天优华占 & No & $6.15 \mathrm{Aa}$ & $3.27 \mathrm{Ab}$ & $21.05 \mathrm{Aa}$ & $6.14 \mathrm{Aa}$ & $5.73 \mathrm{Bb}$ & $3.02 \mathrm{Aa}$ & $23.76 \mathrm{Aa}$ & $11.58 \mathrm{Aa}$ \\
\hline \multirow[t]{3}{*}{ Tianyouhuazhan } & N1 & $6.19 \mathrm{Aa}$ & $3.31 \mathrm{Aab}$ & $18.73 \mathrm{ABb}$ & $5.41 \mathrm{ABab}$ & $5.93 \mathrm{Bb}$ & $3.16 \mathrm{Aa}$ & $19.77 \mathrm{Bb}$ & $9.21 \mathrm{Bb}$ \\
\hline & $\mathrm{N} 2$ & $6.23 \mathrm{Aa}$ & $3.38 \mathrm{Aab}$ & $17.25 \mathrm{ABbc}$ & $4.95 \mathrm{Bb}$ & $6.56 \mathrm{Aa}$ & $3.19 \mathrm{Aa}$ & $15.75 \mathrm{Cc}$ & $6.56 \mathrm{Cc}$ \\
\hline & N3 & $6.33 \mathrm{Aa}$ & $3.45 \mathrm{Aa}$ & $16.21 \mathrm{Bc}$ & $4.20 \mathrm{Bb}$ & $6.75 \mathrm{Aa}$ & $3.24 \mathrm{Aa}$ & $15.23 \mathrm{Cc}$ & $6.54 \mathrm{Cc}$ \\
\hline 黄华占 & N0 & $6.17 \mathrm{Aa}$ & $3.02 \mathrm{Ab}$ & $18.35 \mathrm{Aa}$ & $7.47 \mathrm{Aa}$ & $6.04 \mathrm{Aa}$ & $3.04 \mathrm{Aa}$ & $18.06 \mathrm{Aa}$ & $5.88 \mathrm{Aa}$ \\
\hline \multirow[t]{3}{*}{ Huanghuazhan } & N1 & $6.22 \mathrm{Aa}$ & $3.06 \mathrm{Aab}$ & $17.71 \mathrm{Aa}$ & $6.70 \mathrm{ABa}$ & $6.05 \mathrm{Aa}$ & $3.11 \mathrm{Aa}$ & $14.61 \mathrm{Bb}$ & $4.43 \mathrm{Bb}$ \\
\hline & $\mathrm{N} 2$ & $6.29 \mathrm{Aa}$ & $3.18 \mathrm{Aab}$ & $14.24 \mathrm{Ab}$ & $5.41 \mathrm{Bb}$ & $6.20 \mathrm{Aa}$ & $3.20 \mathrm{Aa}$ & $10.36 \mathrm{Cc}$ & $2.85 \mathrm{Cc}$ \\
\hline & N3 & $6.37 \mathrm{Aa}$ & $3.28 \mathrm{Aa}$ & $7.43 \mathrm{Bc}$ & $4.97 \mathrm{Bb}$ & $6.21 \mathrm{Aa}$ & $3.21 \mathrm{Aa}$ & $9.96 \mathrm{Cc}$ & $2.72 \mathrm{Cc}$ \\
\hline
\end{tabular}

标以不同大、小写字母的值分别在 0.01 和 0.05 水平差异显著。 $\mathrm{N} 0:$ 不施氮肥; $\mathrm{N} 1: 135 \mathrm{~kg} \mathrm{hm}^{-2}$ 纯氮; $\mathrm{N} 2: 180 \mathrm{~kg} \mathrm{hm}^{-2}$ 纯氮; $\mathrm{N} 3: 255 \mathrm{~kg} \mathrm{hm}$ 纯氮。 Values followed by different letters are significantly different at the 0.01 and 0.05 probability levels, respectively. N0: no N applied; N1: 135 $\mathrm{kg} \mathrm{hm}^{-2} \mathrm{~N}$ applied; $\mathrm{N} 2: 180 \mathrm{~kg} \mathrm{hm}^{-2} \mathrm{~N}$ applied; N3: $255 \mathrm{~kg} \mathrm{hm}^{-2} \mathrm{~N}$ applied; KL: kernel length; L/W: ratio of length/width of kernel; CR: chalkiness rate; $\mathrm{CD}$ : chalkiness degree.

\section{表 4 不同氮肥施用量下优质晚稻蒸煮和营养品质}

Table 4 Cooking and nutritional quality of high quality late rice under different nitrogen application rates

\begin{tabular}{|c|c|c|c|c|c|c|c|}
\hline \multirow{2}{*}{$\begin{array}{c}\text { 品种 } \\
\text { Cultivar }\end{array}$} & \multirow{2}{*}{$\begin{array}{c}\text { 处理 } \\
\text { Treatment }\end{array}$} & \multicolumn{3}{|c|}{2017} & \multicolumn{3}{|c|}{2018} \\
\hline & & $\begin{array}{c}\text { 直链淀粉含量 } \\
\text { AC }(\%)\end{array}$ & $\begin{array}{c}\text { 胶稠度 } \\
\text { GC (mm) }\end{array}$ & $\begin{array}{c}\text { 蛋白质含量 } \\
\text { PC (\%) }\end{array}$ & $\begin{array}{c}\text { 直链淀粉含量 } \\
\text { AC }(\%)\end{array}$ & $\begin{array}{c}\text { 胶稠度 } \\
\text { GC (mm) }\end{array}$ & $\begin{array}{c}\text { 蛋白质含量 } \\
\text { PC }(\%)\end{array}$ \\
\hline 美香新占 & No & $19.34 \mathrm{Aa}$ & $62.0 \mathrm{Bc}$ & $6.10 \mathrm{Bc}$ & $17.95 \mathrm{Aa}$ & $63.2 \mathrm{Cc}$ & $6.5 \mathrm{Bc}$ \\
\hline \multirow{3}{*}{$\begin{array}{l}\text { Meixiang } \\
\text { xinzhan }\end{array}$} & N1 & $18.05 \mathrm{ABb}$ & $68.5 \mathrm{ABb}$ & $7.90 \mathrm{Ab}$ & 17.32 Aab & $69.5 \mathrm{Bb}$ & $7.8 \mathrm{Ab}$ \\
\hline & N2 & $17.52 \mathrm{Bbc}$ & $76.5 \mathrm{Aa}$ & $7.95 \mathrm{Ab}$ & 16.19 ABbc & $75.9 \mathrm{Aa}$ & $8.5 \mathrm{Aa}$ \\
\hline & $\mathrm{N} 3$ & $16.90 \mathrm{Bc}$ & $77.5 \mathrm{Aa}$ & $8.80 \mathrm{Aa}$ & $15.94 \mathrm{Bc}$ & $78.3 \mathrm{Aa}$ & $8.9 \mathrm{Aa}$ \\
\hline 泰优 398 & No & $16.46 \mathrm{Aa}$ & $64.5 \mathrm{Bc}$ & $6.35 \mathrm{Dd}$ & $15.53 \mathrm{Aa}$ & $65.9 \mathrm{Ac}$ & $6.6 \mathrm{Cd}$ \\
\hline \multirow[t]{3}{*}{ Taiyou 398} & N1 & 15.74 Aab & $68.0 \mathrm{ABbc}$ & $8.05 \mathrm{Cc}$ & $13.88 \mathrm{Bb}$ & $68.6 \mathrm{Abc}$ & $8.2 \mathrm{Bc}$ \\
\hline & $\mathrm{N} 2$ & $15.26 \mathrm{Ab}$ & $69.5 \mathrm{ABab}$ & $8.70 \mathrm{Bb}$ & $13.57 \mathrm{Bbc}$ & $70.9 \mathrm{Aab}$ & $9.3 \mathrm{ABb}$ \\
\hline & N3 & $15.23 \mathrm{Ab}$ & $73.0 \mathrm{Aa}$ & $9.70 \mathrm{Aa}$ & $12.85 \mathrm{Bc}$ & $73.5 \mathrm{Aa}$ & $10.1 \mathrm{Aa}$ \\
\hline 天优华占 & No & $23.78 \mathrm{Aa}$ & $65.8 \mathrm{Ab}$ & $7.10 \mathrm{Ab}$ & $22.51 \mathrm{Aa}$ & $68.8 \mathrm{Ab}$ & $6.7 \mathrm{Bc}$ \\
\hline \multirow[t]{3}{*}{ Tianyouhuazhan } & N1 & $22.51 \mathrm{ABa}$ & $66.5 \mathrm{Ab}$ & $7.25 \mathrm{Aab}$ & $18.93 \mathrm{Bb}$ & $71.5 \mathrm{Ab}$ & $7.5 \mathrm{ABb}$ \\
\hline & $\mathrm{N} 2$ & $19.53 \mathrm{BCb}$ & $75.8 \mathrm{Aa}$ & 7.35 Aab & $18.26 \mathrm{Bbc}$ & $78.3 \mathrm{Aa}$ & $8.3 \mathrm{Aa}$ \\
\hline & N3 & $19.01 \mathrm{Cb}$ & $76.0 \mathrm{Aa}$ & $7.70 \mathrm{Aa}$ & $17.68 \mathrm{Bc}$ & $79.2 \mathrm{Aa}$ & $8.8 \mathrm{Aa}$ \\
\hline 黄华占 & No & $17.92 \mathrm{Aa}$ & $49.5 \mathrm{Bc}$ & $6.35 \mathrm{Cc}$ & $16.11 \mathrm{Aa}$ & $53.6 \mathrm{Cc}$ & $7.4 \mathrm{Cc}$ \\
\hline \multirow[t]{3}{*}{ Huanghuazhan } & N1 & $15.26 \mathrm{Bb}$ & $56.0 \mathrm{ABb}$ & $8.00 \mathrm{Bb}$ & $14.02 \mathrm{Bb}$ & $60.5 \mathrm{Bb}$ & $8.1 \mathrm{BCb}$ \\
\hline & $\mathrm{N} 2$ & $13.71 \mathrm{Bc}$ & $58.0 \mathrm{Ab}$ & $8.40 \mathrm{ABb}$ & $12.36 \mathrm{Bbc}$ & $62.6 \mathrm{ABb}$ & $8.7 \mathrm{ABb}$ \\
\hline & N3 & $13.41 \mathrm{Bbc}$ & $62.0 \mathrm{Aa}$ & $9.20 \mathrm{Aa}$ & $11.47 \mathrm{Bc}$ & $66.1 \mathrm{Aa}$ & $9.6 \mathrm{Aa}$ \\
\hline
\end{tabular}

标以不同大、小写字母的值分别在 0.01 和 0.05 水平差异显著。 $\mathrm{N} 0:$ 不施氮肥; $\mathrm{N} 1: 135 \mathrm{~kg} \mathrm{hm}^{-2}$ 纯氮; $\mathrm{N} 2: 180 \mathrm{~kg} \mathrm{hm}^{-2}$ 纯氮; $\mathrm{N}^{2}: 255 \mathrm{~kg} \mathrm{hm}{ }^{-2}$ 纯氮。 Values followed by different letters are significantly different at the 0.01 and 0.05 probability levels, respectively. N0: no N applied; N1: 135 $\mathrm{kg} \mathrm{hm}^{-2} \mathrm{~N}$ applied; $\mathrm{N} 2: 180 \mathrm{~kg} \mathrm{hm}^{-2} \mathrm{~N}$ applied; $\mathrm{N} 3: 255 \mathrm{~kg} \mathrm{hm}^{-2} \mathrm{~N}$ applied; AC: amylose; GC: gel consistency; PC: protein content. 
2.2.4 稻米淀粉 RVA 谱特征值 4 个品种的峰值 黏度、热浆黏度、崩解值、最终黏度均随施氮量的 增加而降低, 降低的幅度随品种和施氮量而异, 其 中 N2 与 N3 处理均差异不显著, 但均与 N0 差异显 著或极显著(表 5)。消减值和糊化温度均随施氮量的
增加而增加, 消减值在各氮肥水平处理间均有显著 或极显著差异, 各品种的糊化温度 N3 处理与 N0 处 理差异显著或极显著, 除美香新占外, N2 与 N3 处理 无显著差异。可见施氮量增加使稻米 RVA 谱特性有 变劣趋势。

表 5 不同氮肥施用量下优质晚稻稻米淀粉 RVA 谱特征值(2018)

Table 5 RVA profile characteristics of high quality late rice under different nitrogen application rates (2018)

\begin{tabular}{|c|c|c|c|c|c|c|c|}
\hline $\begin{array}{c}\text { 品种 } \\
\text { Cultivar }\end{array}$ & $\begin{array}{c}\text { 处理 } \\
\text { Treatment }\end{array}$ & $\begin{array}{c}\text { 峰值黏度 } \\
\text { Peak viscosity } \\
(\mathrm{cP})\end{array}$ & $\begin{array}{c}\text { 热浆黏度 } \\
\text { Trough viscosity } \\
(\mathrm{cP})\end{array}$ & $\begin{array}{c}\text { 崩解值 } \\
\text { Breakdown } \\
(\mathrm{cP}) \\
\end{array}$ & $\begin{array}{c}\text { 最终黏度 } \\
\text { Final viscosity } \\
(\mathrm{cP})\end{array}$ & $\begin{array}{c}\text { 消减值 } \\
\text { Setback } \\
\text { (cP) }\end{array}$ & $\begin{array}{c}\text { 糊化温度 } \\
\text { Pasting temperature } \\
\left({ }^{\circ} \mathrm{C}\right)\end{array}$ \\
\hline 美香新占 & No & $3073.0 \mathrm{Aa}$ & $1777.5 \mathrm{Aa}$ & $1295.5 \mathrm{Aa}$ & $3002.5 \mathrm{Aa}$ & $-70.5 \mathrm{Dd}$ & $75.13 \mathrm{Bb}$ \\
\hline \multirow{3}{*}{$\begin{array}{c}\text { Meixiang } \\
\text { xinzhan }\end{array}$} & N1 & $2860.0 \mathrm{ABb}$ & $1691.5 \mathrm{ABab}$ & $1168.5 \mathrm{ABb}$ & $2865.0 \mathrm{ABb}$ & $5.0 \mathrm{Cc}$ & $75.70 \mathrm{ABb}$ \\
\hline & N2 & 2727.0 Bbc & $1676.5 \mathrm{ABb}$ & $1050.5 \mathrm{Bc}$ & $2749.0 \mathrm{BCc}$ & $22.0 \mathrm{Bb}$ & $76.65 \mathrm{ABb}$ \\
\hline & N3 & $2644.5 \mathrm{Bc}$ & $1608.5 \mathrm{Bb}$ & $1036.0 \mathrm{Bc}$ & $2694.0 \mathrm{Cc}$ & $49.5 \mathrm{Aa}$ & $78.23 \mathrm{Aa}$ \\
\hline 泰优 398 & No & $3322.0 \mathrm{Aa}$ & $2036.0 \mathrm{Aa}$ & $1286.0 \mathrm{Aa}$ & $3134.5 \mathrm{Aa}$ & $-187.5 \mathrm{Dd}$ & $75.15 \mathrm{Ab}$ \\
\hline \multirow[t]{3}{*}{ Taiyou 398} & N1 & $3025.0 \mathrm{ABb}$ & 1958.0 ABa & $1067.0 \mathrm{Bb}$ & $2946.5 \mathrm{ABb}$ & $-78.5 \mathrm{Cc}$ & $75.48 \mathrm{Ab}$ \\
\hline & $\mathrm{N} 2$ & $2794.0 \mathrm{ABbc}$ & $1792.5 \mathrm{BCb}$ & $1001.5 \mathrm{BCc}$ & $2833.5 \mathrm{Bbc}$ & $39.5 \mathrm{Bb}$ & $76.35 \mathrm{Aab}$ \\
\hline & N3 & $2641.0 \mathrm{Bc}$ & $1657.0 \mathrm{Cc}$ & $984.0 \mathrm{Cc}$ & $2745.0 \mathrm{Bc}$ & $104.0 \mathrm{Aa}$ & $77.33 \mathrm{Aa}$ \\
\hline 天优华占 & N0 & $2941.5 \mathrm{Aa}$ & $1839.0 \mathrm{Aa}$ & $1102.5 \mathrm{Aa}$ & $3093.5 \mathrm{Aa}$ & $152.0 \mathrm{Cd}$ & $76.75 \mathrm{Ab}$ \\
\hline \multirow[t]{3}{*}{ Tianyouhuazhan } & N1 & $2862.0 \mathrm{ABa}$ & $1838.0 \mathrm{Aa}$ & $1024.0 \mathrm{ABb}$ & 3022.5 Aab & $160.5 \mathrm{Cc}$ & $77.13 \mathrm{Ab}$ \\
\hline & N2 & $2722.5 \mathrm{ABb}$ & $1782.0 \mathrm{Ab}$ & $940.5 \mathrm{Bc}$ & $2920.5 \mathrm{Ab}$ & $198.0 \mathrm{Bb}$ & $78.58 \mathrm{Aa}$ \\
\hline & N3 & $2668.0 \mathrm{Bb}$ & $1728.50 \mathrm{Ab}$ & $939.5 \mathrm{Bc}$ & $2896.5 \mathrm{Ab}$ & $228.5 \mathrm{Aa}$ & $78.78 \mathrm{Aa}$ \\
\hline 黄华占 & No & $3075.5 \mathrm{Aa}$ & $1835.0 \mathrm{Aa}$ & $1240.5 \mathrm{Aa}$ & $2923.5 \mathrm{Aa}$ & $-152.0 \mathrm{Dd}$ & $72.50 \mathrm{Bb}$ \\
\hline \multirow[t]{3}{*}{ Huanghuazhan } & N1 & $2895.5 \mathrm{ABb}$ & 1759.5 Aab & $1136.0 \mathrm{ABb}$ & $2805.0 \mathrm{ABb}$ & $-90.5 \mathrm{Cc}$ & $73.65 \mathrm{ABb}$ \\
\hline & $\mathrm{N} 2$ & $2785.0 \mathrm{Bbc}$ & $1696.0 \mathrm{Ab}$ & 1089.0 Bbc & $2747.5 \mathrm{Bb}$ & $-37.5 \mathrm{Bb}$ & 74.15 ABab \\
\hline & $\mathrm{N} 3$ & $2698.0 \mathrm{Bc}$ & $1638.0 \mathrm{Ab}$ & $1060.0 \mathrm{Bc}$ & $2740.5 \mathrm{Bb}$ & $42.5 \mathrm{Aa}$ & $75.63 \mathrm{Aa}$ \\
\hline
\end{tabular}

标以不同大、小写字母的值分别在 0.01 和 0.05 水平差异显著。 $\mathrm{N} 0:$ 不施氮肥; $\mathrm{N} 1: 135 \mathrm{~kg} \mathrm{~h}^{-2}$ 纯氮; $\mathrm{N} 2: 180 \mathrm{~kg} \mathrm{hm}^{-2}$ 纯氮; $\mathrm{N} 3: 255 \mathrm{~kg} \mathrm{hm}^{-2}$ 纯氮。

Values followed by different letters are significantly different at the 0.01 and 0.05 probability levels, respectively. N0: no $\mathrm{N}$ applied; $\mathrm{N} 1: 135 \mathrm{~kg}$ $\mathrm{hm}^{-2} \mathrm{~N}$ applied; $\mathrm{N} 2: 180 \mathrm{~kg} \mathrm{hm}^{-2} \mathrm{~N}$ applied; $\mathrm{N} 3: 255 \mathrm{~kg} \mathrm{hm}^{-2} \mathrm{~N}$ applied.

\section{3 产量、稻米品质和 RVA 谱特征值的方差分} 析和相关分析

\subsection{1产量及构成因素的方差分析＼cjkstart方差分析} 表明(表 6), 产量及构成因素在年份、品种、氮肥 用量及年份与品种互作间均差异显著或极显著, 穗数、每穗粒数、总颖花量、产量在年份与氮肥 用量互作间差异显著或极显著, 在品种与氮肥用 量互作间差异极显著。可见, 产量及构成因素在年 度间有差异, 除受品种特性影响外, 还受氮肥施 用量的明显影响。除穗数外, 产量及构成因素年 份、品种和氮肥三者互作间差异不显著。可见氮 肥用量、品种及年度均对优质晚稻产量及构成因

\section{素有较大影响。}

\subsection{2 稻米品质及淀粉 RVA 谱特征值的方差分析} 稻米品质各指标和 RVA 谱特征值在品种、氮肥 用量及年份与品种互作间差异达到显著或极显著水 平。除了糙米率和精米率外, 各指标在年份间也有 极显著差异(表 7)。除粘米率、籽粒长宽比、糊化温 度外, 稻米品质各指标与 RVA 谱特征值在品种与氮 肥用量两因子互作间差异显著或极显著。严白率、 严白度、直链淀粉含量、胶稠度、崩解值、消减值 等在年份、品种和氮肥三者互作间差异达到极显著 水平。各指标在年度间的差异, 除受品种自身遗传 特性影响外, 还受氮肥施用量的显著影响。 
表 6 不同氮肥施用量下优质晚稻产量及构成因素的方差分析

Table 6 Variance analysis of yield and components of high quality late rice under different nitrogen application rates

\begin{tabular}{|c|c|c|c|c|c|c|c|}
\hline $\begin{array}{c}\text { 变异来源 } \\
\text { Source of variation }\end{array}$ & $\begin{array}{c}\text { 年份 } \\
\mathrm{Y}\end{array}$ & $\begin{array}{c}\text { 品种 } \\
\mathrm{C}\end{array}$ & $\begin{array}{c}\text { 氮肥用量 } \\
\mathrm{N}\end{array}$ & $\begin{array}{c}\text { 年份 } \times \text { 品种 } \\
\qquad \times \mathrm{C}\end{array}$ & $\begin{array}{c}\text { 年份×氮肥 } \\
\text { 用量 } \\
\mathrm{Y} \times \mathrm{N} \\
\end{array}$ & $\begin{array}{c}\text { 品种 } \times \text { 氮肥 } \\
\text { 用量 } \\
\mathrm{C} \times \mathrm{N} \\
\end{array}$ & $\begin{array}{c}\text { 年份 } \times \text { 品种 } \times \\
\text { 氮肥用量 } \\
\mathrm{Y} \times \mathrm{C} \times \mathrm{N}\end{array}$ \\
\hline 自由度 $\mathrm{df}$ & 1 & 3 & 3 & 3 & 3 & 9 & 9 \\
\hline 穗数 Panicle & $5.901^{*}$ & $77.14^{* *}$ & $207.66^{* *}$ & $24.78^{* *}$ & $4.36^{*}$ & $3.82^{* *}$ & $4.02^{* *}$ \\
\hline 每穗粒数 Spikelets per panicle & $152.87^{* *}$ & $296.40^{* *}$ & $408.01^{* *}$ & $21.06^{* *}$ & $17.81^{* *}$ & $19.28^{* *}$ & 1.62 \\
\hline 总颖花量 Total number of spikelets & $210.24^{* *}$ & $321.75^{* *}$ & $1093.84^{* *}$ & $68.89^{* *}$ & $8.42^{* *}$ & $11.22^{* *}$ & 1.54 \\
\hline 结实率 Filled-grain percentage & $9.93^{* *}$ & $57.27^{* *}$ & $18.05^{* *}$ & $33.18^{* *}$ & 1.54 & 0.92 & 0.35 \\
\hline 千粒重 1000-kernel weight & $61.28^{* *}$ & $201.49^{* *}$ & $7.07^{* *}$ & $4.97^{* *}$ & 0.07 & 1.41 & 0.31 \\
\hline 产量 Yield & $4.37^{*}$ & $32.19^{* *}$ & $713.21^{* *}$ & $9.56^{* *}$ & $14.47^{* *}$ & $7.51^{* *}$ & 0.95 \\
\hline$F_{0.05}$ & 4.16 & 2.91 & 2.91 & 2.91 & 2.91 & 2.19 & 2.19 \\
\hline$F_{0.01}$ & 7.53 & 4.48 & 4.48 & 4.48 & 4.48 & 3.04 & 3.04 \\
\hline
\end{tabular}

"和"*分别表示达到 0.05 和 0.01 显著水平。

* and ${ }^{* *}$ indicate significant difference at $P=0.05$ and $P=0.01$, respectively. Y: year; C: cultivar; $\mathrm{N}$ : nitrogen application.

表 7 不同氮肥施用量下机插优质晚稻稻米品质及淀粉 RVA 谱特性的方差分析

Table 7 Variance analysis of rice quality and starch RVA profile characteristics of high quality late rice under different nitrogen application rates

\begin{tabular}{|c|c|c|c|c|c|c|c|}
\hline $\begin{array}{c}\text { 变异来源 } \\
\text { Source of variation }\end{array}$ & $\begin{array}{c}\text { 年份 } \\
\mathrm{Y}\end{array}$ & $\begin{array}{c}\text { 品种 } \\
\mathrm{C}\end{array}$ & $\begin{array}{c}\text { 氮肥用量 } \\
\mathrm{N}\end{array}$ & $\begin{array}{c}\text { 年份 } \times \text { 品种 } \\
\mathrm{Y} \times \mathrm{C}\end{array}$ & $\begin{array}{c}\text { 年份 } \times \text { 氮肥用量 } \\
\mathrm{Y} \times \mathrm{N}\end{array}$ & $\begin{array}{c}\text { 品种 } \times \text { 氮肥用量 } \\
\mathrm{C} \times \mathrm{N}\end{array}$ & $\begin{array}{c}\text { 年份×品种 } \times \\
\text { 氮肥用量 } \\
\mathrm{Y} \times \mathrm{C} \times \mathrm{N}\end{array}$ \\
\hline 自由度 df & 1 & 3 & 3 & 3 & 3 & 9 & 9 \\
\hline 糙米率 $\mathrm{BR}$ & 1.85 & $4.09^{*}$ & $10.73^{* *}$ & $5.12^{* *}$ & 1.77 & 0.58 & 0.83 \\
\hline 精米率 MR & 0.46 & $7.96^{* *}$ & $11.52^{* *}$ & $4.17^{*}$ & 0.58 & $2.24^{*}$ & 1.14 \\
\hline 整精米率 HMR & $41.85^{* *}$ & $409.36^{* *}$ & $65.81^{* *}$ & $11.92^{* *}$ & 0.76 & $15.25^{* *}$ & 0.54 \\
\hline 长宽比 L/W & $33.99^{* *}$ & $11.76^{* *}$ & $18.89^{* *}$ & $61.26^{* *}$ & 1.90 & 0.39 & 0.53 \\
\hline 严白粒率 CR & $2011.08^{* *}$ & $2241.82^{* *}$ & $1185.19^{* *}$ & $3517.08^{* *}$ & $30.86^{* *}$ & $37.38^{* *}$ & $26.37^{* *}$ \\
\hline 普白度 CD & $616.49^{* *}$ & $7547.28^{* *}$ & $2116.79^{* *}$ & $8743.70^{* *}$ & $154.42^{* *}$ & $52.60^{* *}$ & $99.76^{* *}$ \\
\hline 直链淀粉含量 $\mathrm{AC}$ & $385.15^{* *}$ & $1162.91^{* *}$ & $326.03^{* *}$ & $8.88^{* *}$ & $5.38^{* *}$ & $20.13^{* *}$ & $6.28^{* *}$ \\
\hline 蛋白质含量 PC & $57.15^{* *}$ & $439.02^{* *}$ & $277.98^{* *}$ & $8.77^{* *}$ & 0.32 & $9.84^{* *}$ & 0.37 \\
\hline 胶稠度 $\mathrm{GC}$ & $69.15^{* *}$ & $62.814^{* *}$ & $515.17^{* *}$ & $3.46^{*}$ & $5.72^{* *}$ & $16.93^{* *}$ & $5.73^{* *}$ \\
\hline 峰值黏度 PKV & $10.43^{* *}$ & $18.63^{* *}$ & $113.98^{* *}$ & $11.16^{* *}$ & 2.13 & $6.07^{* *}$ & 0.50 \\
\hline 热浆黏度 THV & $46.93^{* *}$ & $93.56^{* *}$ & $33.68^{* *}$ & $38.51^{* *}$ & $17.88^{* *}$ & $14.35^{* *}$ & 1.86 \\
\hline 崩解值 BKD & $486.79^{* *}$ & $85.67^{* *}$ & $516.85^{* *}$ & $83.93^{* *}$ & $15.58^{* *}$ & $5.28^{* *}$ & $8.78^{* *}$ \\
\hline 最终黏度 FLV & $19.92^{* *}$ & $78.08^{* *}$ & $18.96^{* *}$ & $28.89^{* *}$ & $8.84^{* *}$ & $3.79^{* *}$ & 0.88 \\
\hline 消减值 STB & $769.98^{* *}$ & $30348.16^{* *}$ & $16690.88^{* *}$ & $7333.67^{* *}$ & $1416.93^{* *}$ & $409.35^{* *}$ & $359.09^{* *}$ \\
\hline 糊化温度 PAT & $58.79^{* *}$ & $89.87^{* *}$ & $3.75^{*}$ & $52.58^{* *}$ & 0.53 & 0.10 & 0.14 \\
\hline$F_{0.05}$ & 4.16 & 2.91 & 2.91 & 2.91 & 2.91 & 2.19 & 2.19 \\
\hline$F_{0.01}$ & 7.53 & 4.48 & 4.48 & 4.48 & 4.48 & 3.04 & 3.04 \\
\hline
\end{tabular}

"和"“分别表示达到 0.05 和 0.01 显著水平。

${ }^{*}$ and ${ }^{* *}$ indicate significant difference at $P=0.05$ and $P=0.01$, respectively. Y: year; C: cultivar; $\mathrm{N}$ : nitrogen application; BR: brown rice rate; MR: milled rice rate; HMR: head milled rice rate; $\mathrm{L} / \mathrm{W}$ : ratio of length/width of kernel; $\mathrm{CR}$ : chalkiness rate; $\mathrm{CD}$ : chalkiness degree; $\mathrm{AC}$ : amylose; PC: protein content; GC: gel consistency; PKV: peak viscosity; THV: trough viscosity; BKD: breakdown; FLV: final viscosity; STB: setback; PAT: pasting temperature.

\subsection{3 稻米品质指标的相关分析 除精米率与整} 精米率显著正相关外，加工品质各指标间无显著相 关性, 糙米率、精米率与峰值黏度、崩解值显著负
相关，整精米率与直链淀粉含量、胶稠度、消减值、 最终黏度、糊化温度等极显著正相关，与崩解值显 著负相关。严白度与严白粒率间极显著正相关，二 
者与直链淀粉含量、蛋白质含量极显著或显著相关, 其中严白粒率还与峰值黏度、热浆黏度、崩解值、最 终黏度极显著正相关。从蒸煮食味品质各指标、 RVA 谱特征值间的相关性看, 直链淀粉含量与蛋白质含 量极显著负相关, 与最终黏度极显著正相关, 与胶稠 度相关性不显著, 蛋白质含量与峰值黏度、热浆黏 度、崩解值、最终黏度等极显著或显著负相关(表 8$)$ 。

2.4 灌浆结实期温光资源与稻米品质

机插条件下各优质晚稻品种灌浆结实期的日平 均温度、日最高温度、日最低温度、日平均温差和 日平均光照时数均随氮肥施用量增加呈下降趋势 (表 9)。

从加工品质看, 精米率与日平均温度和日最 低温度极显著或显著负相关, 整精米率与日平均 光照时数显著负相关(表 10)。从外观品质看, 严白 粒率与日平均温度和日最高温度极显著或显著正 相关, 粒长、长宽比与日平均温差显著或极显著负 相关。从 RVA 谱特征值看, 峰值黏度、热浆秥度 及最终黏度与日平均温度和日最高温度极显著正 相关, 崩解值与日平均日照时数极显著正相关, 而消减值、糊化温度与日平均日照时数极显著或 显著负相关。

\section{3 讨论}

\section{1 氮肥施用量对机插优质晚稻产量及构成因 素的影响}

水稻产量受遗传基因与环境互作的影响, 还与 水稻生长发育过程中的栽培技术条件有很大关系, 其中氮肥对水稻产量及构成因素影响很大。适宜 的施氮量是水稻高产、稳产的重要保障 ${ }^{[18]}$ 。魏海 燕等 ${ }^{[19]}$ 研究表明, 随氮肥用量的增加, 超级粳稻的 产量先增加后下降, 增加产量的主要原因是在适当 的氮肥施用量下, 超级粳稻有较高的群体颖花量。 成臣等 ${ }^{[20]}$ 研究认为, 随施氮量增加, 南方晚粳稻产 量先增加后下降, 其中有效穗数、每穗粒数与产量 呈极显著正相关, 与结实率呈极显著负相关, 而与 千粒重无显著相关。徐新朋等 ${ }^{[11]}$ 研究发现, 在施氮 水平达到 $180 \mathrm{~kg} \mathrm{hm}^{-2}$ 时, 早稻和晚稻的产量达到最 大, 施氮量与水稻产量呈抛物线关系, 增施氮肥提 高早稻和晚稻的单位面积有效穗数, 但当施氮量超 $180 \mathrm{~kg} \mathrm{hm}^{-2}$ 时, 穗粒数开始降低。本研究中, 在施氮 量为 $0 \sim 180 \mathrm{~kg} \mathrm{hm}^{-2}$ 的范围内, 机插优质双季晚稻的 群体颖花量、每穗粒数和产量随施氮量增加而增加,
这可能是因为适量的增施氮肥能提高水稻光合作用, 更好地促进水稻成长和形成较多的同化产物, 促进 颖花分化, 增加颖果内容量, 利于提高水稻产量。 但当施氮量增加到 $255 \mathrm{~kg} \mathrm{hm}^{-2}$ 时, 因群体过大导 致个体优势削弱, 每穗粒数下降, 产量也出现下降 趋势, 这与施氮量过多导致水稻营养过剩, 贪青晚 熟有关 ${ }^{[21]}$ 。对于机插优质双季晚稻, 因穗数不足或 抗性差导致产量不高, 常优质不高产。氮肥对水稻 的有效穗数和穗粒数影响较大 ${ }^{[22]}$, 本研究中适量增 施氮肥能增加水稻的有效穗数、每穗粒数, 增加群 体颖花量和有效颖花量, 进而增加优质晚稻产量。 氮肥过多会降低每穗粒数、结实率和千粒重, 导致 产量降低。过多施用氮肥造成优质高产不协调, 多 数优质稻因抗性不如一般高产水稻, 在高氮下容易 倒伏, 既影响产量, 也不利于优质。优质稻黄华占在 长江中下游一般作单季晚稻种植, 当机插双季晚稻 种植时, 播期适当推迟也能正常成熟。

双季晚稻的机械化种植方式除了机插积外, 还 有机直播。王春雨等 ${ }^{[23]}$ 研究表明, 在同一施氮水平 下, 机插产量高, 而直播稻平均减产 $10 \%$ 以上。机插 水稻有利于增加成穗率和单穗重, 而直播则主要通 过增加穗数来实现高产 ${ }^{[24]}$, 汪和廷等 ${ }^{[25]}$ 进一步研究 发现直播下水稻有效穗数高于机插方式, 但其穗粒 数和千粒重低, 导致低产。直播稻因生育期较短, 虽 群体较大, 但个体生长不够健壮, 抽穗前后单株物 质积累量较低, 而机插种植方式在施氮量相对少的 条件下，水稻能实现高产，减氮优化施肥产量没有 显著降低。机插优质晚稻较机直播能更稳靠地实现 产量和氮素利用效率的提高。

3.2 氮肥施用量对机插优质晚稻稻米品质的 影响

稻米品质不仅取决于水稻的基因型，也取决于 生长时的肥料条件、土壤类型、气候条件及种植方 式 ${ }^{[26-27]}$ 。万靚军等 ${ }^{[28]}$ 研究表明, 增施氮肥显著改善 稻米外观品质, 增加稻米蛋白质含量, 降低直链淀 粉含量, 改善稻米营养品质。殷春渊等 ${ }^{[29]}$ 研究认为, 增加氮肥施用量使水稻严白粒率和严白度呈增加趋 势, 直链淀粉和蛋白质含量也基本表现上升趋势。 本研究中, 施氮量在 $0 \sim 180 \mathrm{~kg} \mathrm{hm}^{-2}$ 的范围内, 机插 优质双季晚稻的糙米率、精米率及整精米率随着施 氮的增加而增加, 严白粒率、严白度均随施氮量的 增加而减小, 可见适当增施氮改善了稻米的加工和 外观品质。这可能因为适当增施氮肥提高群体和个 


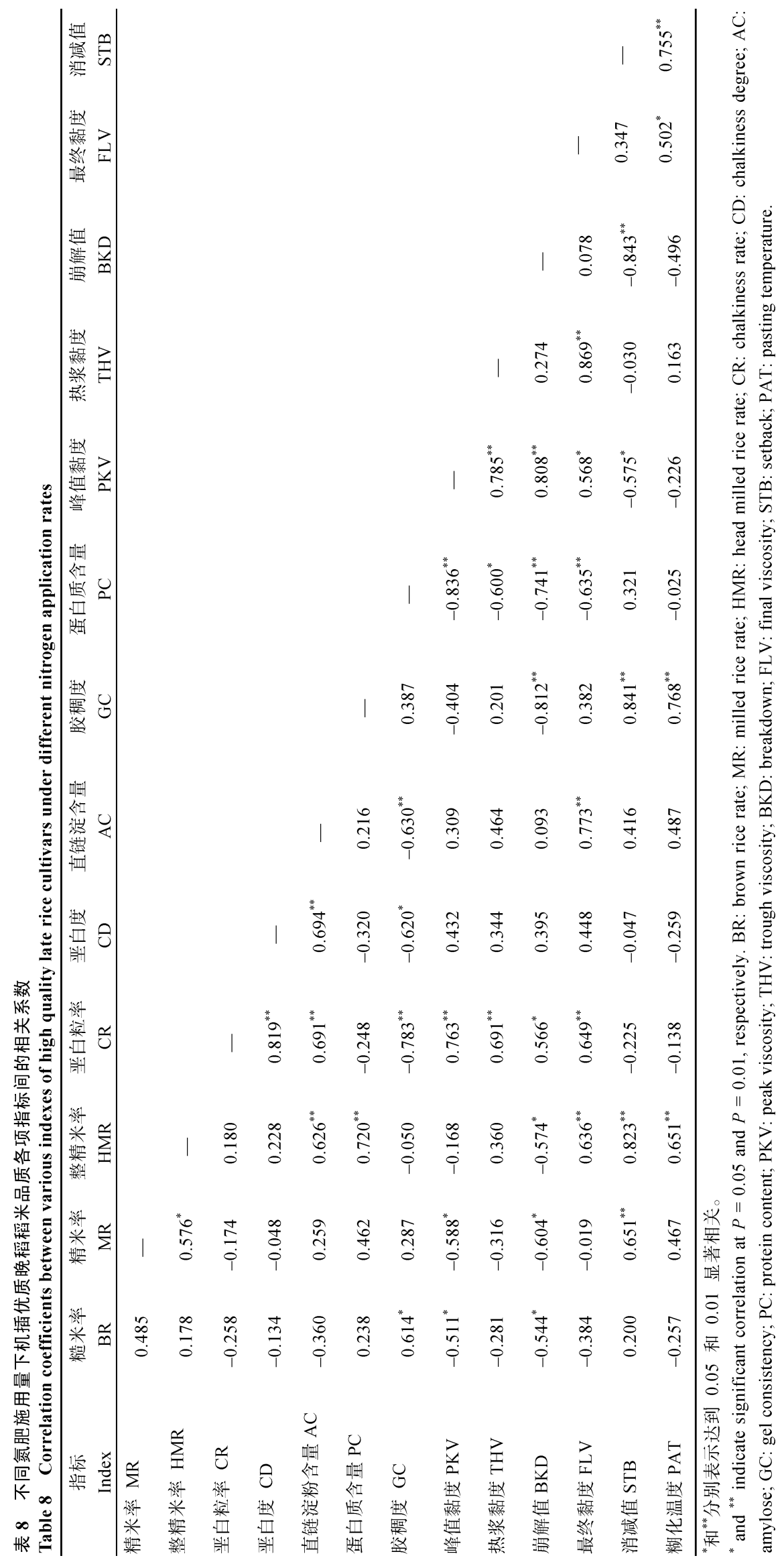


表 9 各处理灌浆结实期的温光情况

Table 9 Temperature and light factors during filling stage

\begin{tabular}{|c|c|c|c|c|c|c|}
\hline $\begin{array}{c}\text { 品种 } \\
\text { Cultivar }\end{array}$ & $\begin{array}{c}\text { 处理 } \\
\text { Treatment }\end{array}$ & $\begin{array}{c}\text { 日平均温度 } \\
\text { Daily mean } \\
\text { temperature }\left({ }^{\circ} \mathrm{C}\right)\end{array}$ & $\begin{array}{c}\text { 日最高温度 } \\
\text { Daily maximum } \\
\text { temperature }\left({ }^{\circ} \mathrm{C}\right)\end{array}$ & $\begin{array}{c}\text { 日最低温度 } \\
\text { Daily minimum } \\
\text { temperature }\left({ }^{\circ} \mathrm{C}\right)\end{array}$ & $\begin{array}{c}\text { 日平均温差 } \\
\text { Daily mean } \\
\text { temperature } \\
\text { difference }\left({ }^{\circ} \mathrm{C}\right)\end{array}$ & $\begin{array}{c}\text { 日平均光照时数 } \\
\text { Daily mean } \\
\text { illumination } \\
\text { hours }(\mathrm{h})\end{array}$ \\
\hline \multicolumn{7}{|l|}{2017} \\
\hline 美香新占 & No & 20.34 & 23.97 & 16.81 & 7.16 & 7.14 \\
\hline \multirow[t]{3}{*}{ Meixiangxinzhan } & N1 & 20.41 & 23.18 & 16.24 & 6.94 & 6.87 \\
\hline & N2 & 19.52 & 22.98 & 16.11 & 6.87 & 6.54 \\
\hline & N3 & 19.14 & 22.78 & 15.98 & 6.80 & 6.17 \\
\hline 泰优 398 & No & 23.87 & 25.49 & 19.68 & 5.81 & 6.87 \\
\hline \multirow[t]{3}{*}{ Taiyou 398} & N1 & 23.24 & 25.12 & 19.37 & 5.75 & 6.69 \\
\hline & $\mathrm{N} 2$ & 22.17 & 24.41 & 19.25 & 5.16 & 6.26 \\
\hline & N3 & 19.98 & 24.19 & 19.07 & 5.12 & 5.76 \\
\hline 天优华占 & No & 22.56 & 25.17 & 18.23 & 6.94 & 6.58 \\
\hline \multirow[t]{3}{*}{ Tianyouhuazhan } & N1 & 21.49 & 24.98 & 18.25 & 6.73 & 6.12 \\
\hline & N2 & 21.05 & 24.52 & 17.92 & 6.60 & 5.56 \\
\hline & N3 & 19.88 & 23.91 & 17.24 & 6.67 & 5.24 \\
\hline 黄华占 & No & 22.59 & 25.74 & 17.86 & 7.88 & 6.97 \\
\hline \multirow[t]{3}{*}{ Huanghuazhan } & N1 & 22.11 & 25.24 & 17.53 & 7.71 & 6.68 \\
\hline & N2 & 21.47 & 24.56 & 16.97 & 7.59 & 6.25 \\
\hline & N3 & 20.41 & 23.87 & 16.54 & 7.33 & 6.16 \\
\hline \multicolumn{7}{|l|}{2018} \\
\hline 美香新占 & No & 21.02 & 25.06 & 17.03 & 8.03 & 7.05 \\
\hline \multirow[t]{3}{*}{ Meixiangxinzhan } & N1 & 20.56 & 24.33 & 16.54 & 7.79 & 6.98 \\
\hline & $\mathrm{N} 2$ & 19.61 & 23.57 & 15.69 & 7.88 & 6.57 \\
\hline & N3 & 19.41 & 23.12 & 15.40 & 7.72 & 6.21 \\
\hline 泰优 398 & No & 24.90 & 26.57 & 21.28 & 5.29 & 6.66 \\
\hline \multirow[t]{3}{*}{ Taiyou 398} & N1 & 23.45 & 25.98 & 20.95 & 5.03 & 6.25 \\
\hline & $\mathrm{N} 2$ & 22.35 & 24.56 & 20.41 & 4.15 & 5.78 \\
\hline & N3 & 22.04 & 24.22 & 19.88 & 4.34 & 5.52 \\
\hline 天优华占 & No & 22.76 & 26.32 & 19.23 & 7.09 & 6.15 \\
\hline \multirow[t]{3}{*}{ Tianyouhuazhan } & N1 & 22.46 & 26.12 & 18.84 & 7.28 & 5.57 \\
\hline & $\mathrm{N} 2$ & 21.15 & 25.74 & 18.35 & 7.39 & 5.68 \\
\hline & N3 & 20.94 & 25.16 & 18.02 & 7.14 & 5.21 \\
\hline 黄华占 & No & 22.75 & 26.63 & 18.91 & 7.72 & 6.72 \\
\hline \multirow[t]{3}{*}{ Huanghuazhan } & N1 & 22.13 & 25.93 & 18.46 & 7.47 & 6.34 \\
\hline & N2 & 21.58 & 25.12 & 18.17 & 6.95 & 5.97 \\
\hline & N3 & 20.97 & 24.95 & 17.76 & 7.19 & 6.04 \\
\hline
\end{tabular}

N0: 不施氮肥; $\mathrm{N} 1: 135 \mathrm{~kg} \mathrm{hm}^{-2}$ 纯氮; $\mathrm{N} 2: 180 \mathrm{~kg} \mathrm{hm}^{-2}$ 纯氮; $\mathrm{N} 3: 255 \mathrm{~kg} \mathrm{hm}^{-2}$ 纯氮。

N0: no N applied; N1: $135 \mathrm{~kg} \mathrm{hm}^{-2} \mathrm{~N}$ applied; N2: $180 \mathrm{~kg} \mathrm{hm}^{-2} \mathrm{~N}$ applied; N3: $255 \mathrm{~kg} \mathrm{hm}^{-2} \mathrm{~N}$ applied. 
表 10 稻米品质特征与灌浆结实期温光因子间的相关系数

Table 10 Correlation coefficients between rice quality characters and temperature and light factors during grain-filling period

\begin{tabular}{|c|c|c|c|c|c|}
\hline $\begin{array}{l}\text { 指标 } \\
\text { Index }\end{array}$ & $\begin{array}{c}\text { 日平均温度 } \\
\text { Daily mean } \\
\text { temperature }\left({ }^{\circ} \mathrm{C}\right)\end{array}$ & $\begin{array}{c}\text { 日最高温度 } \\
\text { Daily maximum } \\
\text { temperature }\left({ }^{\circ} \mathrm{C}\right)\end{array}$ & $\begin{array}{c}\text { 日最低温度 } \\
\text { Daily minimum } \\
\text { temperature }\left({ }^{\circ} \mathrm{C}\right)\end{array}$ & $\begin{array}{c}\text { 日平均温差 } \\
\text { Daily mean } \\
\text { temperature } \\
\text { difference }\left({ }^{\circ} \mathrm{C}\right)\end{array}$ & $\begin{array}{c}\text { 日平均光照时数 } \\
\text { Daily mean } \\
\text { illumination } \\
\text { hours (h) }\end{array}$ \\
\hline 䊁米率 $\mathrm{BR}$ & -0.328 & -0.451 & -0.120 & -0.207 & -0.473 \\
\hline 精米率 MR & $-0.712^{* *}$ & -0.470 & $-0.593 *$ & 0.406 & -0.116 \\
\hline 整精米率 HMR & -0.246 & -0.075 & -0.119 & 0.097 & $-0.505^{*}$ \\
\hline 粒长 KL & -0.202 & -0.458 & 0.095 & $-0.498^{*}$ & -0.449 \\
\hline 长宽比 L/W & 0.031 & -0.493 & 0.277 & $-0.768^{* *}$ & -0.202 \\
\hline 垩白率 CR & $0.554^{*}$ & $0.668^{* *}$ & 0.397 & 0.016 & 0.178 \\
\hline 普白度 CD & 0.398 & $0.664^{* *}$ & 0.280 & 0.167 & -0.159 \\
\hline 直链淀粉含量 $\mathrm{AC}$ & -0.056 & 0.229 & -0.200 & 0.451 & 0.099 \\
\hline 蛋白质含量 PC & -0.457 & $-0.541^{*}$ & -0.259 & -0.095 & $-0.540^{*}$ \\
\hline 胶稠度 GC & -0.400 & $-0.596^{*}$ & -0.096 & -0.357 & $-0.588^{*}$ \\
\hline 峰值秥度 PKV & $0.737^{* *}$ & $0.685^{* *}$ & 0.486 & -0.089 & $0.614^{*}$ \\
\hline 热浆黏度 THV & $0.869^{* *}$ & $0.793^{* *}$ & $0.749^{* *}$ & -0.350 & 0.169 \\
\hline 崩解值 BKD & 0.353 & 0.343 & 0.055 & 0.206 & $0.861^{* *}$ \\
\hline 最终黏度 FLV & $0.680^{* *}$ & $0.758^{* *}$ & $0.506^{*}$ & -0.057 & 0.187 \\
\hline 消减值 STB & -0.401 & -0.236 & -0.212 & 0.077 & $-0.747^{* *}$ \\
\hline 糊化温度 PAT & -0.394 & -0.422 & -0.202 & -0.075 & $-0.609^{*}$ \\
\hline
\end{tabular}

"和*”分别表示达到 0.05 和 0.01 显著相关。

" and " indicate significant correlation at $P=0.05$ and $P=0.01$, respectively. BR: brown rice rate; MR: milled rice rate; HMR: head milled rice rate; KL: kernel length; $\mathrm{L} / \mathrm{W}$ : ratio of length/width of kernel; CR: chalkiness rate; CD: chalkiness degree; AC: amylose; PC: protein content; GC: gel consistency; PKV: peak viscosity; THV: trough viscosity; BKD: breakdown; FLV: final viscosity; STB: setback; PAT: pasting temperature.

体优势，延长了灌浆结实期时间，使灌浆缓慢，籽 粒内物分配合理, 致密性增强 ${ }^{[30]}$ 。本研究中机插优 质双季晚稻蛋白质含量随着施氮量增加而提高, 这 可能是由于氮肥的施用促进了氨基酸和蛋白质的合 成。有关施氮量对稻米直链淀粉含量和胶稠度的影 响, 前人的研究结果不尽相同。张洪程等 ${ }^{[31]}$ 和从夕 汉等 ${ }^{[32]}$ 研究表明, 随施氮量的增加, 稻米的直链淀 粉含量和胶稠度变大。高辉等 ${ }^{[33]}$ 认为, 随施氮量的 增加, 各生育期类型水稻的直链淀粉含量均降低, 胶稠度略有缩短。张自常等 ${ }^{[34]}$ 结果表明, 施氮量的 增加使稻米直链淀粉含量降低, 胶稠度变长。本研 究中随着施氮量的增加, 机插优质双季晚稻品种的 直链淀粉含量减少, 胶稠度增加, 这可能是蛋白质 含量与直链淀粉含量的互补效应有关, 即蛋白质含 量高, 直链淀粉含量低。以上研究结果存在差异, 可 能是各地品种对肥料的反应不同造成，另外各试验 所处温光环境不同, 也影响品种对氮肥的响应效 应。根据优质籼稻谷质量标准，施氮量从 0 增至 $180 \mathrm{~kg} \mathrm{hm}^{-2}$, 美香新占的出䊁率、严白粒率和胶稠度
等从国家二级提高到一级, 泰优 398 的严白度和胶 稠度从国家二级提高到一级，黄华占的整精米率从 等外提高到三级，胶稠度从三级提高到二级，天优 华占严白度由等外提高到国家三级, 胶稠度从二级 提高到一级。可见适当增施氮肥能改善机插优质晚 稻的稻米品质。本研究发现优质稻黄华占作为机插 双季晚稻的胶稠度偏低, 这可能生育期推迟降低胶 稠度有关 ${ }^{[35]}$, 黄华占作为机插双季晚稻的播期较作 为一季中稻或一季晚稻的播期推迟，抽穗灌浆期相 应推迟, 全生育缩短 5 10d。

稻米 RVA 谱特征值是评价稻米食味品质的一个 重要理化指标 ${ }^{[36]}$ 。优质食味稻米的 RVA 谱参数值, 通常表现为崩解值大、最终黏度小、消减值小和糊 化温度低的基本特性 ${ }^{[37]}$ 。关于氮肥施用对稻米淀粉 RVA 谱特性的影响，前人研究结果不尽一致。张国 生等 ${ }^{[38]}$ 认为, 随氮肥施用量的增加, 稻米淀粉 RVA 谱的峰值黏度、热浆黏度和崩解值上升, 而消减值 和糊化温度下降, 但胡雅杰等 ${ }^{[39]}$ 等研究表明, 稻米 淀粉 RVA 谱的峰值黏度和崩解值随氮肥施用量增加 
有所降低, 而热浆黏度和消减值则呈上升趋势。本 文中机插栽培条件下, 随施氮量的增加, 机插优质 双季晚稻品种的峰值黏度、热浆黏度、崩解值、最 终黏度逐渐下降, 而消减值和糊化温度逐渐增加。 说明施氮量对优质晚稻稻米淀粉黏滞性存在一定负 效应, 增施氮肥一定程度上不利于优质晚稻淀粉黏 滞性的形成。这可能是增施氮肥使稻米蛋白质含量 增加所致, 因为填塞在淀粉颗粒间的蛋白质对淀粉 粒的糊化和膨胀起抑制作用，使淀粉粒间空隙减小， 吸水速率变慢, 使米饭黏度低、较为松散、硬度大 ${ }^{[40]}$, 从而影响口感, 食味品质变劣。本研究也发现, 黄华 占和泰优 398 的峰值黏度较美香新占和天优华占高, 消减值、糊化温度以及直链淀粉含量较美香新占和 天优华占低, 说明黄华占和泰优 398 的食味品质较 美香新占和天优华占有一定优势。

\section{4 结论}

随着氮肥施用量增加, 机插优质晚稻的穗数增 加、每穗粒数先增后减, 结实率降低, 千粒重有所下 降, 产量先增后减并在 $180 \mathrm{~kg} \mathrm{hm}^{-2}$ 施氮量时最高。 适量增施氮肥, 机插优质晚稻的加工品质、外观品 质、蒸煮和营养品质得到改善, 但 RVA 谱特征值有 变劣趋势。 $180 \mathrm{~kg} \mathrm{hm}^{-2}$ 施氮量是机插优质双季晚稻 实现优质高产协调的最适施氮量。

\section{References}

[1] Yu Q G, Ye J, Yang S N, Fu J R, Ma J W, Sun W C, Jiang L N, Wang Q, Wang J M. Effects of nitrogen application level on rice nutrient uptake and ammonia volatilization. Rice Sci, 2013, 20: 139-147.

[2] Xiang L K, Ping Z, Zhong Q S, Jin S B. Physicochemical properties of starches from diverse rice cultivars varying in apparently amylose content and gelatinisation temperature combinations. Food Chem, 2015, 172: 433-440.

[3] 程方民, 刘正辉, 张峪午. 稻米品质形成的气候生态条件评价 及我国地域分布规律. 生态学报, 2002, 22: 636-642.

Cheng F M, Liu Z H, Zhang S W. The evaluation of climatic-ecology condition for the rice quality formation and its distribution laws in China. Acta Ecol Sin, 2002, 22: 636-642 (in Chinese with English abstract).

[4] Hayashi S, Kamoshita A, Yamagishi J, Kotchasatit A, Jongdee B. Genotypic differences in grain yield of transplanted and direct-seeded rainfed lowland rice (Oryza sativa L.) in northeastern Thailand. Field Crops Res, 2007, 102: 9-21.

[5] Lanning S B, Siebenmorgen T J, Counce P A, Ambardekar A A, Mauromoustakos A. Extreme nighttime air temperatures in 2010 impact rice chalkiness and milling quality. Field Crops Res, 2011, 124: 132-136.

[6] Jun F G, Jing C, Lu C, Zhi Q W, Hao Z, Jian C Y. Grain quality changes and responses to nitrogen fertilizer of japonica rice cultivars released in the Yangtze river basin from the 1950s to 2000s. Crop J, 2015, 3: 285-297.

[7] Nowotna A, Gambuś H, Kratsch G. Effect of nitrogen fertilization on the physicochemical properties of starch isolated from German triticale varieties. Starch-Stärke, 2007, 59: 397-399.

[8] Peng S B, Buresh R J, Huang J L, Yang J C, Zou Y B, Zhong X H, Wang G G, Zhang F S. Strategies for overcoming low agronomic nitrogen use efficiency in irrigated rice systems in china. Field Crops Res, 2006, 96: 37-47.

[9] 王秀斌, 徐新朋, 孙刚, 孙静文, 梁国庆, 刘光荣, 周卫. 氮肥 用量对双季稻产量和氮肥利用率的影响. 植物营养与肥料学 报, 2013, 19: 1279-1286.

Wang X B, Xu X M, Sun G, Sun J W, Liang G Q, Liu G R, Zhou W. Effects of nitrogen fertilization on grain yield and nitrogen use efficiency of double cropping rice. J Plant Nutr Fert, 2013, 19: 1279-1286 (in Chinese with English abstract).

[10] 郭保卫, 胡雅杰, 钱海军, 曹伟伟, 邢志鹏, 张洪程, 戴其根, 霍中洋, 许轫, 魏海燕. 秸秆还田下适宜施氮量提高机插稻南 粳 9108 产量和群体质量. 中国水稻科学, 2015, 29: 511-518. Guo B W, Hu Y J, Qian H J, Cao W W, Xing Z P, Zhang H C, Dai Q G, Xu K, Wei H Y. Optimal nitrogen rate improves grain yield and population quality of mechanical transplanted rice Nanjing 9108 under straw manuring. Chin J Rice Sci, 2015, 29: 511-518 (in Chinese with English abstract).

[11] 徐新朋, 周卫, 梁国庆, 孙静文, 王秀斌, 何萍, 徐芳森, 余喜初. 氮肥用量和密度对双季稻产量及氮肥利用率的影 响. 植物营养与肥料学报, 2015, 21: 763-772.

Xu X M, Zhou W, Liang G Q, Sun J W, Wang X B, He P, Xu F $S$, Yu X C. Effects of nitrogen and density interactions on grain yield and nitrogen use efficiency of double-rice systems. J Plant Nutr Fert, 2015, 21: 763-772 (in Chinese with English abstract).

[12] 李敏, 张洪程, 李国业, 马群, 杨雄, 魏海燕. 生育类型与施 氮水平对粳稻淀粉 RVA 谱特性的影响. 作物学报, 2012, 38: 293-300.

Li M, Zhang H C, Li G Y, Ma Q, Yang X, Wei H Y. Effects of growth-period type and nitrogen application level on the RVA profile characteristics for japonica rice genotypes. Acta Agron Sin, 2012, 38: 293-300 (in Chinese with English abstract).

[13] 马群, 张洪程, 戴其根, 魏海燕, 霍中洋, 许轫, 殷春渊, 杭杰, 张胜飞, 张庆. 生育类型与施氮水平对粳稻加工品质的影响. 作物学报, 2009, 35: 1282-1289.

Ma Q, Zhang H C, Dai Q G, Wei H Y, Huo Z Y, Xu K, Yin C Y, Hang J, Zhang S F, Zhang Q. Effects of nitrogen application rate and growth-development type on milling quality in japonica rice. Acta Agron Sin, 2009, 35: 1282-1289 (in Chinese with English abstract).

[14] 朱大伟. 三种关键栽培措施对软米粳稻产量与品质的影响. 扬州大学博士学位论文, 江苏扬州, 2018.

Zhu D W. Effects of Three Key Cultivation Measures on Yield and Quality of Soft Rice Japonica Rice. PhD Dissertation of Yangzhou University, Yangzhou, Jiangsu, China, 2018 (in Chinese with English abstract).

[15] 金正勋, 秋太权, 孙艳丽, 赵久明, 金学泳. 氮肥对稻米严白 及蒸煮食味品质特性的影响. 植物营养与肥料学报, 2001, 7: 
31-35.

Jin Z X, Qiu T Q, Sun Y L, Zhao J M, Jin X Y. Effects of nitrogen fertilizer on chalkness ratio and cooking and eating quality properties of rice grain. Plant Nutr Fert Sci, 2001, 7: 31-35 (in Chinese with English abstract).

[16] 金军, 徐大勇, 蔡一霞, 胡署云, 葛敏, 朱庆森. 施氮量对水 稻主要米质性状及 RVA 谱特征参数的影响. 作物学报, 2004, 30: 154-158.

Jin J, Xu D Y, Cai Y X, Hu S Y, Ge M, Zhu Q S. Effect of $\mathrm{N}$-fertilizer on main quality characters of rice and RVA profile parameters. Acta Agron Sin, 2004, 30: 154-158 (in Chinese with English abstract).

[17] 郭保卫, 朱大伟, 朱聪聪, 许轫, 周兴涛, 张洪程, 陈厚存, 张 军, 陈京都, 戴其根, 霍中洋, 魏海燕, 曹利强, 李明银. 有序 摆抛栽对粳型超级稻稻米品质的影响. 作物学报, 2015, 41: 487-498.

Guo B W, Zhu D W, Zhu C C, Xu K, Zhou X T, Zhang H C, Chen H C, Zhang J ,Chen J D, Dai Q G, Huo Z Y, Wei H Y, Cao L Q, Li M Y. Effect of ordered transplanting and optimized broadcasting on japonica super rice quality. Acta Agron Sin, 2015, 41: 487-498 (in Chinese with English abstract).

[18] Zhou W, Lyu T F, Zhang P P. Regular nitrogen application increases nitrogen utilization efficiency and grain yield in indica hybrid rice. Agron J, 2016, 108: 1951-1961.

[19] 魏海燕, 王亚江, 孟天瑶, 葛梦婕, 张洪程, 戴其根, 霍中洋, 许轫. 机插超级粳稻产量、品质及氮肥利用率对氮肥的响应. 应用生态学报, 2014, 25: 488-496.

Wei H Y, Wang Y J, Meng T Y, Ge M J, Zhang H C, Dai Q G, Huo Z Y, Xu K. Response of yield, quality and nitrogen use efficiency to nitrogen fertilizer from mechanical transplanting super japonica rice. Chin J Appl Ecol, 2014, 25: 488-496 (in Chinese with English abstract).

[20] 成臣, 曾勇军, 王祺, 谭雪明, 商庆银, 曾研华, 石庆华. 施氮 量对晚粳稻甬优 1538 产量、品质及氮素吸收利用的影响. 水 土保持学报, 2018, 32: 222-228.

Cheng C, Zeng Y J, Wang Q, Tan X M, Shang Q H, Zeng Y H, Shi Q H. Effects of nitrogen application rates on japonica rice yield, quality, and nitrogen uptake and utilization during the late-rice cropping seasons in southern China. J Soil \& Water Conserv, 2018, 32: 222-228 (in Chinese with English abstract).

[21] 张建军, 贾哲, 涂强, 张党省, 张效瑕. 不同施氮量对汉中稻 区晚熟稻产量及稻米品质的影响. 西北农业学报, 2014, 23(8): 60-65.

Zhang J J, Jia Z, Tu Q, Zhang D S, Zhang X J. Effects of different rates of nitrogen application on the yield and quality of late-maturing rice in Hanzhong. Acta Agric Boreali-Occident Sin, 2014, 23(8): 60-65 (in Chinese with English abstract).

[22] 韩宝吉, 曾祥明, 卓光毅, 徐芳森, 姚忠清, 肖习明, 石磊. 施 用措施对湖北中稻产量、品质和氮肥利用率的影响. 中国农业 科学, 2011, 44: 842-850.

Han B J, Zeng X M, Zhuo G Y, Xu F S, Yao Z Q, Xiao X M, Shi L. Effects of fertilization measures of nitrogen $(\mathrm{N})$ on grain yield, grain quality and $\mathrm{N}$-use efficiency of midseason rice in Hubei province. Sci Agric Sin, 2011, 44: 842-850 (in Chinese with English abstract).

[23] 王春雨, 余华清, 何艳, 郭长春, 张绍文, 杨志远, 马均. 播栽
方式与施氮量对杂交籼稻氮肥利用特征及产量的影响. 中国 生态农业学报, 2017, 25: 1792-1801.

Wang C Y, Yu H Q, He Y, Guo C C, Zhang S W, Yang Z Y, Ma J. Characteristics of nitrogen accumulation and utilization in indica hybrid rice under different planting methods and nitrogen rates. Chin J Eco-Agric, 2017, 25: 1792-1801 (in Chinese with English abstract).

[24] 伍丹丹, 谢小兵, 陈佳娜, 刍应斌. 种植方式对水稻生长发育 和产量的影响. 作物研究, 2014, 28(1): 92-96.

Wu D D, Xie X B, Chen J N, Zou Y B. Effects of planting methods on rice growth and yield. Crop Res, 2014, 28(1): 92-96 (in Chinese with English abstract).

[25] 汪和廷, 董慧, 齐龙昌, 李学松, 王腾, 宋贺, 陈松, 董召荣, 章秀福. 种植方式及施氮量对水稻灌浆初期氮代谢关键酶活 性和产量性状的影响。中国生态农业学报，2015，23: 1210-1214.

Wang H Y, Dong H, Qi L C, Li X S, Wang T, Song H, Chen S, Dong Z R, Zhang X F. Effects of cultivation method and nitrogen application rate on key enzyme activities of nitrogen metabolism at early milky stage and grain yield of rice. Chin J Eco-Agric, 2015, 23: 1210-1214 (in Chinese with English abstract).

[26] Falade K O, Semon M, Fadairo O S, Oladunjoye A O, Orou K $\mathrm{K}$. Functional and physico-chemical properties of flours and starches of African rice cultivars. Food Hydrocolloids, 2014, 39: 41-50.

[27] Wu F F, Chen H Y, Na Y, Wang J P, Duan X, Jin Z Y, Xu X M. Effect of germination time on physicochemical properties of brown rice flour and starch from different rice cultivars. $J$ Cereal Sci, 2013, 58: 263-271.

[28] 万鉦军, 张洪程, 霍中洋, 林忠成, 戴其根, 许轫, 张军. 氮肥 运筹对超级杂交粳稻产量、品质及氮素利用率的影响. 作物学 报, 2007, 33: 175-182.

Wan J J, Zhang H C, Huo Z Y, Lin Z C, Dai Q G, Xu K, Zhang J. Effects of nitrogen application regimes on yield, quality, and nitrogen use efficiency of super japonica hybrid rice. Acta Agron Sin, 2007, 33: 175-182 (in Chinese with English abstract).

[29] 殷春沸, 王书玉, 刘贺梅, 孙建权, 胡秀明, 薛应征, 王和乐, 范永胜. 不同密度和施氮量对稻米品质特性的影响. 河南农 业科学, 2015, 44(9): 15-18.

Yin C Y, Wang S Y, Liu H M, Sun J Q, Hu X M, Xue Y Z, Wang H L, Fan Y S. Effects of different planting density and amount of nitrogen fertilizer on rice quality characteristics. $J$ Henan Agric Sci, 2015, 44(9): 15-18 (in Chinese with English abstract).

[30] 龚金龙, 张洪程, 胡雅杰, 龙厚元, 常勇, 王艳, 邢志鹏, 霍中 洋. 灌浆结实期温度对水稻产量和品质形成的影响. 生态学 杂志, 2013, 32: 482-491.

Gong J L, Zhang H C, Hu Y J, Long H Y, Chang Y, Wang Y, Xing Z P, Huo Z Y. Effects of air temperature during rice grain filling period on the formation of rice grain yield and its quality. Chin $J$ Ecol, 2013, 32: 482-491 (in Chinese with English abstract).

[31] 张洪程, 王秀芹, 戴其根, 霍中洋, 许轫. 施氮量对杂交稻 两优培九产量、品质及吸氮特性的影响. 中国农业科学, 2003, 36: 800-806.

Zhang H C, Wang X Q, Dai Q G, Huo Z Y, Xu K. Effects of $\mathrm{N}$-application rate on yield, quality and characters of nitrogen uptake of hybrid rice variety Liangyoupeijiu. Sci Agric Sin, 2003, 
36: 800-806 (in Chinese with English abstract).

[32] 从夕汉, 施伏芝, 阮新民, 罗玉祥, 马廷臣, 罗志祥. 氮肥水 平对不同基因型水稻氮素利用率、产量和品质的影响. 生态学 报, 2017, 28: 1219-1226.

Cong X H, Shi F Z, Ruan X M, Luo Y X, Ma Z C, Luo Z X. Effects of nitrogen fertilizer application rate on nitrogen use efficiency and grain yield and quality of different rice varieties. Chin J Appl Ecol, 2017, 28: 1219-1226 (in Chinese with English abstract).

[33] 高辉, 马群, 李国业, 杨雄, 李雪侨, 殷春渊, 李敏, 张庆, 张洪程, 戴其根, 魏海燕. 氮肥水平对不同生育类型粳稻 稻米蒸煮食味品质的影响. 中国农业科学, 2010, 43: 4543-4552.

Gao H, Ma Q, Li G Y, Yang X, Li X Q, Yin C Y, Li M, Zhang Q, Zhang H C, Dai Q G, Wei H Y. Effect of nitrogen application rate on cooking and eating qualities of different growth-development types of japonica rice. Sci Agric Sin, 2010, 43: 4543-4552 (in Chinese with English abstract).

[34] 张自常, 李鸿伟, 曹转勤, 王志琴, 杨建昌. 施氮量和灌溉方 式的交互作用对水稻产量和品质影响. 作物学报, 2013，39: 84-92.

Zhang Z C, Li H W, Cao Z Q, Wang Z Q, Yang J C. Effect of interaction between nitrogen rate and irrigation regime on grain yield and quality of rice. Acta Agron Sin, 2013, 39: 84-92 (in Chinese with English abstract).

[35] 成臣, 曾勇军, 吕伟生, 谭雪明, 商庆银, 曾研华, 石庆华. 南 方稻区优质晚粳稻产量和品质调优的播期效应. 核农学报, 2018, 32: 2019-2030.

Cheng C, Zeng Y J, Lyu W S, Tan X M, Shang Q Y, Zeng Y H, Shi Q H. Effect of sowing date on rice yield and quality of high-quality japonica rice during the late-rice cropping seasons in southern china. J Nucl Agric Sci, 2018, 32: 2019-2030 (in Chinese with English abstract).
[36] 叶全宝, 张洪程, 李华, 霍中洋, 魏海燕, 夏科, 戴其根, 许轫. 施氮水平和栽插密度对粳稻淀粉 RVA 谱特性的影响. 作物学 报, 2005, 31: 124-130.

Ye Q B, Zhang H C, Li H, Huo Z Y, Wei H Y, Xia K, Dai Q G, Xu $\mathrm{K}$. Effects of amount of nitrogen applied and planting density on RVA profile characteristic of japonica rice. Acta Agron Sin, 2005, 31: 124-130 (in Chinese with English abstract).

[37] 问影, 张丽霞, 万常照, 曹黎明, 吴书俊. 稻米淀粉 RVA 谱特 征值及理化指标与食味值的相关性. 植物生理学报, 2016, 52: 1884-1890.

Yan Y, Zhang L X, Wan C Z, Cao L M, Wu S J. Correlation analysis between taste value and RVA profile characteristics as well as physical/chemical indicator in rice. Plant Physiol $J$, 2016, 52: 1884-1890 (in Chinese with English abstract).

[38] 李国生, 张耗, 王志琴, 刘立军, 杨建昌. 氮素水平对水稻 产量与品质的影响. 扬州大学学报(农业与生命科学版), 2007, 28(4): 66-70.

Li G S, Zhang H, Wang Z Q, Liu L J, Yang J C. Effects of nitrogen levels on grain yield and quality of rice. J Yangzhou Univ (Agric \& Life Sci Edn), 2007, 28(4): 66-70 (in Chinese with English abstract).

[39] 胡雅杰, 钱海军, 吴培, 朱明, 邢志鹏, 戴其根, 霍中洋, 魏海 燕, 许轫, 张洪程. 秸秆还田条件下氮磷钾用量对软米粳稻产 量和品质的影响. 植物营养与肥料学报, 2018, 24: 817-824. Hu Y J, Qian H J, Wu P, Zhu M, Xing Z P, Dai Q G, Huo Z Y, Wei H Y, Xu K, Zhang H C. Effects of nitrogen, phosphorus and potassium fertilizer rates on yield and grain quality of soft japonica rice under straw returning condition. J Plant Nutr Fert, 2018, 24: 817-824 (in Chinese with English abstract).

[40] Zhu D W, Zhang H C, Guo B W, Xu K, Dai Q G, Wei C X, Wei H Y, Gao H, Hu Y J, Cui P Y, Huo Z Y. Effect of nitrogen management on the structure and physicochemical properties of rice starch. J Agric Food Chem, 2016, 64: 8019-8025. 